\title{
EL PALIMPSESTO COMO UNA PUERTA DE ACCESO A DIFERENTES TEMPORALIDADES: EL CASO DE RÍO LAS SALINAS 2 (TUCUMÁN, ARGENTINA)
}

\author{
PALIMPSESTS AS A GATEWAY TO DIFFERENT TEMPORALITIES: \\ THE CASE OF Rio Las SALinas 2 (TUCUMAN, ARgENTina).
}

Carolina Somonte $^{1}$ y Carlos A. Baied ${ }^{2}$

They [palimpsests] are not some distorted or degraded version of a message that needs to be restored to its original state before it can be interpreted. To a large extent they are the message. (Bailey 2007: 209)

\begin{abstract}
Resumen
En este trabajo discutimos la utilidad del concepto de palimpsesto como herramienta teórico-metodológica en la descomposición del paisaje arqueológico en unidades analíticas apropiadas para la evaluación de la variabilidad en las historias de uso del espacio. Se tuvieron en cuenta indicadores de condiciones de estabilidad a escalas del paisaje y de los artefactos en RLS2. Desde el paisaje, evaluamos procesos geomorfológicos de las superficies y del pavimento donde se encuentran depositados los conjuntos líticos. A nivel de artefactos consideramos análisis tipológicos, los efectos de alteraciones post-depositacionales en las rocas y tareas de ensamblaje. Ello nos permitió detectar condiciones de mayor y menor estabilidad, asociadas a un pavimento con grados variables de madurez sobre los que actúan procesos naturales que, en conjunto, repercuten sobre las condiciones de hallazgo. En un extremo, asociamos la estabilidad a sectores donde el pavimento muestra cierto grado de preservación, con un correlato a escala del artefacto donde el barniz de las rocas y el ensamblaje la ratifican. En el extremo opuesto, detectamos condiciones de inestabilidad que resultan de procesos erosivos en sectores donde el pavimento muestra distintos grados de deterioro hasta su total desaparición, sugiriendo las distintas condiciones a las que estuvieron expuestos los materiales arqueológicos.
\end{abstract}

Palabras claves: Estabilidad del paisaje - conjuntos artefactuales líticos - arqueología - geoarqueología.

\begin{abstract} In order to evaluate variability in land-use histories we discuss the usefulness of the concept of palimpsest as a theoretical-methodological tool that can be used to analyze and break up archaeological landscape structures into suitable analytical units. Through a case study we assess indicators of stability at both the landscape and artifact levels. At the landscape level, we discussed geomorphological processes operating at the site, focusing particularly at desert pavement. At the artifact level we apply typological analysis and looked into the effects of post-depositional alterations in rocks and artifacts. Research results suggest both conditions of greater and lesser stability associated to desert pavement that shows differential degrees of maturity shaping discovery conditions. At one end, stability is associated to places where pavement shows a certain degree of preservation, with a correlate at scale of the artifact where rock varnish and the possibility of artifact refitting supports stability. At the other end, we identified conditions of instability, marked by erosion processes operating in areas where pavement is partially to completely deteriorate. In between these ends, a variety of hues in pavement preservation speaks to de differential conditions to which artifacts were exposed.
\end{abstract}

Keywords: Landscape stability - lithic artifact scatters - archaeology - geoarchaeology.

Recibido: diciembre 2015. Aceptado: marzo 2017.

\section{* Introducción}

Bailey (2007) sostiene que el término palimpsesto, en su acepción más frecuente, alude a escenarios de superposición y solapamiento de sucesivas actividades realizadas a lo largo de períodos variables de tiempo, las que dan lugar a un paisaje en el que la evidencia de las ocupaciones más antiguas ha sido prácticamente 'borrada' por aquéllas más recientes. Esta aproximación, sin embargo, tiene distintos alcances. Por una parte, esta concepción de los palimpsestos involucra la pérdida total de la información relacionada con las ocupaciones, con excepción de las más recientes. Escenarios como éste presentan un número de desventajas (handicap) al momento de interpretar el registro arqueológico, ya que este último se manifestaría distorsionado, sesgado e incompleto y necesitaría ser re-ordenado o reestructurado. Compartimos con Bailey (2007) la idea de que esta visión repercute negativamente en las posibilidades reales que ofrecen los palimpsestos como una herramienta o fuente de información en sí misma.

Indistintamente, los palimpsestos pueden ser vistos como el resultado de la acumulación y transformación de actividades sucesivas, parcialmente preservadas, que generan paisajes mucho más complejos que la mera suma (y resta) de episodios puntuales (Bailey 2007). Esta perspectiva no apunta a la pérdida y destrucción de la evidencia, sino a la valoración de las propiedades acumulativas y transformadoras del registro arqueológico (por ejemplo Binford 1981; Schiffer 1987; Bailey 1981, 2008; Wandsnider 1998; Barton 2003; Holdaway et al. 2008; Borrero 2014; Barrientos et al. 2014; Davies et al. 2015). Desde esta mirada, los palimpsestos son concebidos como la consecuencia de procesos que crean, a escalas variables, un patrón espacial en el registro factible de ser identificado e interpretado

1 Instituto de Arqueología y Museo, Universidad Nacional de Tucumán - Instituto Superior de Estudios Sociales (CONICET). San Martín 1545 (CP 4000), San Miguel de Tucumán, Tucumán, ARGENTINA. Email: carosomonte@hotmail.com

2 Centro de Investigaciones en Ecología Histórica (CIEH). Facultad de Ciencias Naturales e Instituto Miguel Lillo, Universidad Nacional de Tucumán. Miguel Lillo 205 (CP 4000), San Miguel de Tucumán, Tucumán, ARGENTINA. Email: cbaied@yahoo.com 
(Holdaway et al. 2008). Este concepto se aleja de la idea de un registro en desventaja $y$, por el contrario, apuesta a convertir esas 'limitaciones' en una virtud.

Por otro lado, los palimpsestos constituyen la forma usual en que se presenta el registro arqueológico (Hodaway y Wandsnider 2006; Bailey 2007, entre otros). Así, la noción de palimpsesto denota múltiples episodios de depositación, temporalmente secuenciales, causados independientemente por agentes naturales o antrópicos (Malinsky-Buller et al. 2011), donde las distorsiones del registro, lejos de poder ser rectificadas, deben ser entendidas y usadas para seleccionar escalas de análisis apropiadas (Borrero 2014). También es cierto que no todos los palimpsestos son iguales, y en el uso del término, se combinan $y$, a menudo, se enmascaran varias escalas temporales y espaciales de los procesos de formación (Malinsky-Buller et al. 2011). Modificar la escala temporal y espacial desde las cuales hacemos nuestras observaciones cambia lo que 'vemos'. Esa variación en las escalas repercute, además, en las diferentes variables y procesos sobre los que focalizamos nuestras investigaciones, muchos de los cuales no son visibles, o no son fácilmente visibles, en otra escala temporal y espacial (Holdaway y Wandsnider 2008; Bailey 2007; Barton 2003).

Las investigaciones arqueológicas que estamos llevando a cabo en la vertiente occidental de Cumbres Calchaquíes y Sierras del Aconquija apuntan a la comprensión de la historia ocupacional de espacios persistentes (sensu Schlanger 1992). Estos espacios se caracterizan por un registro de superficie con evidencia de diversas historias ocupacionales; superposición de las mismas; ausencia -hasta el momento- de materiales orgánicos datables mediante técnicas convencionales; presencia de pátinas, el barniz de las rocas la más frecuente entre artefactos; soportes con arte rupestre y diversas estructuras arquitectónicas; indicios de diferentes momentos de ejecución en las representaciones rupestres y procesos de reclamación arquitectónica y artefactual (Somonte y Baied 2011; Adris 2013; Somonte y Baied 2013; Baied y Somonte 2013). Esta diversidad de situaciones comunicadas por el registro arqueológico da cuenta de la complejidad de estos espacios. Lo expresado hace que estemos preocupados por (y ocupados en) estudiar la configuración de estos espacios persistentes, abordando el estudio de un palimpsesto (o múltiples palimpsestos) cuya estructura pretendemos explicar a partir del análisis de condiciones de estabilidad a escalas del paisaje y los artefactos líticos.

Para tal fin evaluamos indicadores de condiciones de estabilidad a partir de ambas escalas. Con respecto al paisaje, analizamos la dinámica geomorfológica de la superficie de glacis donde se encuentran los conjuntos líticos. A nivel de artefactos, consideramos las alteraciones posdepositacionales, como pátinas (barniz de las rocas y iron film) y grados de abrasión, a lo que se suman las tareas de ensamblaje de los conjuntos, incluyendo el remontaje y la reparación de piezas depositadas en esta superficie. A partir de la identificación y definición de condiciones de mayor o menor estabilidad en Río Las Salinas 2, nuestro caso de estudio, discutimos la utilidad del concepto de palimpsesto como herramienta teórico-metodológica en la des-composición del paisaje arqueológico en unidades analíticas apropiadas para la evaluación de la variabilidad en las historias de uso del espacio (Holdaway y Wandsnider 2006).

\section{Estabilidad: definición e indicadores}

Por definición, una superficie estable es aquélla que existe por un espacio significativo de tiempo y, por lo tanto, es capaz de contener o representar un agregado de ocupaciones distintas (Davies et al. 2015; Dibble et al. 2016). Para que esto sea así, la exposición de materiales arqueológicos a determinadas condiciones debe darse durante un lapso prolongado (Borrero 2006; Borrazzo 2006, entre otros). La condición de mayor o menor estabilidad de una superficie puede evaluarse a través de ciertos indicadores visibles y medibles en el paisaje y en los conjuntos artefactuales. Entre los indicadores asociados a condiciones de mayor estabilidad en ambientes áridos, se encuentra el denominado barniz de las rocas, una película que se le forma en la superficie compuesta por minerales arcillosos cementados por óxidos de manganeso y hierro (Dorn 2009, 2007). La naturaleza acrecional de esta pátina requiere de cierto tiempo de depositación (Dorn y Oberlander 1982; Liu y Dorn 1996; Quade 2001; Somonte y Collantes 2010). En aquellos lugares donde el barniz recubre clastos y artefactos líticos, es claro que el tiempo transcurrido desde la depositación del artefacto y la formación de la pátina misma fue significativo (miles de años). Esto solo pudo tener lugar en el marco de una relativa estabilidad del paisaje. 
Un segundo indicador de estabilidad es el ensamblaje (sensu Ramos 1993), término abarcativo para referirse a los remontajes y las reparaciones. El remontaje alude a la recolocación, en las relaciones espaciales preexistentes a su separación, de dos o más artefactos (por ejemplo la reconstitución de un núcleo y sus lascas). Si bien el remontaje informa acerca del orden en el cual fueron removidas las lascas de un núcleo, no comunica quién los removió (un tallador o varios talladores) o el tiempo involucrado en la reducción de dicho núcleo (Dibble et al. 2016). El hecho de que existan piezas que puedan ser remontadas, independientemente del tiempo real involucrado en ese evento de talla (que pudo ser más de uno), da cuenta de ciertas condiciones de estabilidad en el paisaje. La reparación subsana el efecto de una fractura, al recolocar los fragmentos de una unidad en su relación estructural original, concluyendo en el objeto unido o reparado (Ramos 1993). La posibilidad de reparación permite sostener, también, que estos artefactos han estado bajo condiciones de una relativa estabilidad.

Por otra parte, entre los indicadores de condiciones de menor estabilidad o cierta inestabilidad, se encuentra el grado de abrasión de las piezas, visto como un indicador importante de exposición aérea y por tanto útil a la hora de discutir grados de exposición diferencial de los conjuntos líticos a la erosión eólica e hídrica.

Teniendo en cuenta los indicadores que acabamos de describir, la estabilidad puede ser entendida como una condición del paisaje, caracterizada por la ausencia de importantes cambios y que se mantiene por un período determinado. En este trabajo pretendemos identificar, a través de un caso de estudio proveniente del noroeste argentino, condiciones de mayor y menor estabilidad a nivel del paisaje y cómo éstas se reflejan en los artefactos.

\section{Características generales del área de estudio}

El área de trabajo se inserta dentro del ambiente morfoestructural de las Sierras Pampeanas, caracterizado en el noroeste tucumano por la presencia de dos cordones montañosos: Sierras del Aconquija y Cumbres Calchaquíes, separados entre sí por una depresión tectónica de rumbo NW-SE que coincide en el SE con el valle de Tafí y en el NW con la quebrada de Amaicha (Mon y Mansilla 1998) (Figura 1A). La vertiente occidental de esta diviso- ria de aguas presenta un paisaje sedimentario complejo, caracterizado por eventuales afloramientos de areniscas de origen Terciario sobre las que se asientan conos de deyección de origen fluvial, gravas de gran porte, y depósitos que resultan de movimientos en masa vinculados a deslizamientos poco profundos, flujos y avalanchas de detritos, asociados a pedimentos (glacis) de pendiente suave (Strecker et al. 1989). Estos glacis se encuentran cubiertos por una delgada cobertura detrítica constituida por rocas del basamento cristalino y vulcanitas (Durando et al. 1986). La distribución espacial de este complejo paisaje se halla controlada por las precipitaciones (como factor desencadenante), por la orientación y grado de inclinación de las pendientes, su litología (o grado de meteorización de los materiales que conforman las geoformas), y por procesos erosivos de origen antrópico (vinculados al uso del suelo) y naturales (vinculados al escurrimiento superficial, vientos y bioturbación primordialmente).

El clima es del tipo desértico frío, con precipitación pluvial que rara vez supera los $200 \mathrm{~mm}$ anuales, concentrada durante los meses de noviembre a marzo (Sesma et al. 1998). El mayor porcentaje de lluvias se produce entre octubre y abril, con un déficit hídrico elevado, de aproximadamente $500 \mathrm{~mm}$ anuales (Tineo 2005). El área presenta una marcada variación de la temperatura diaria y estacional con medias anuales que varían entre los 14 y $16{ }^{\circ} \mathrm{C}$, siendo la media de enero de $20{ }^{\circ} \mathrm{C}$ y la media de julio de $8{ }^{\circ} \mathrm{C}$ (Tineo 2005). Collantes y González (2012) sostienen que la variabilidad climática estacional y multianual actual, sumadas al uso excesivo de la tierra (como uno de los factores fundamentales de la presión antrópica) generaron una larga cadena de procesos de desertificación, que condujeron a la destrucción de la capacidad de regeneración de la cubierta vegetal necesaria o suficiente para proteger la superficie del suelo, de la erosión. Así, el paisaje hoy está restringido a un estrato arbustivo esparcido y monótono, rodeado por suelos altamente degradados, con escasos árboles en áreas con alguna disponibilidad de humedad. En este contexto geoambiental y antropogénico, tienen lugar procesos geomorfológicos tales como erosión hídrica (laminar, surcos y cárcavas), erosión y sedimentación eólica, pavimento (o pedregosidad), formación de badlands, formación o reactivación de dunas, salinización y encostramiento de suelos, remoción y transporte 


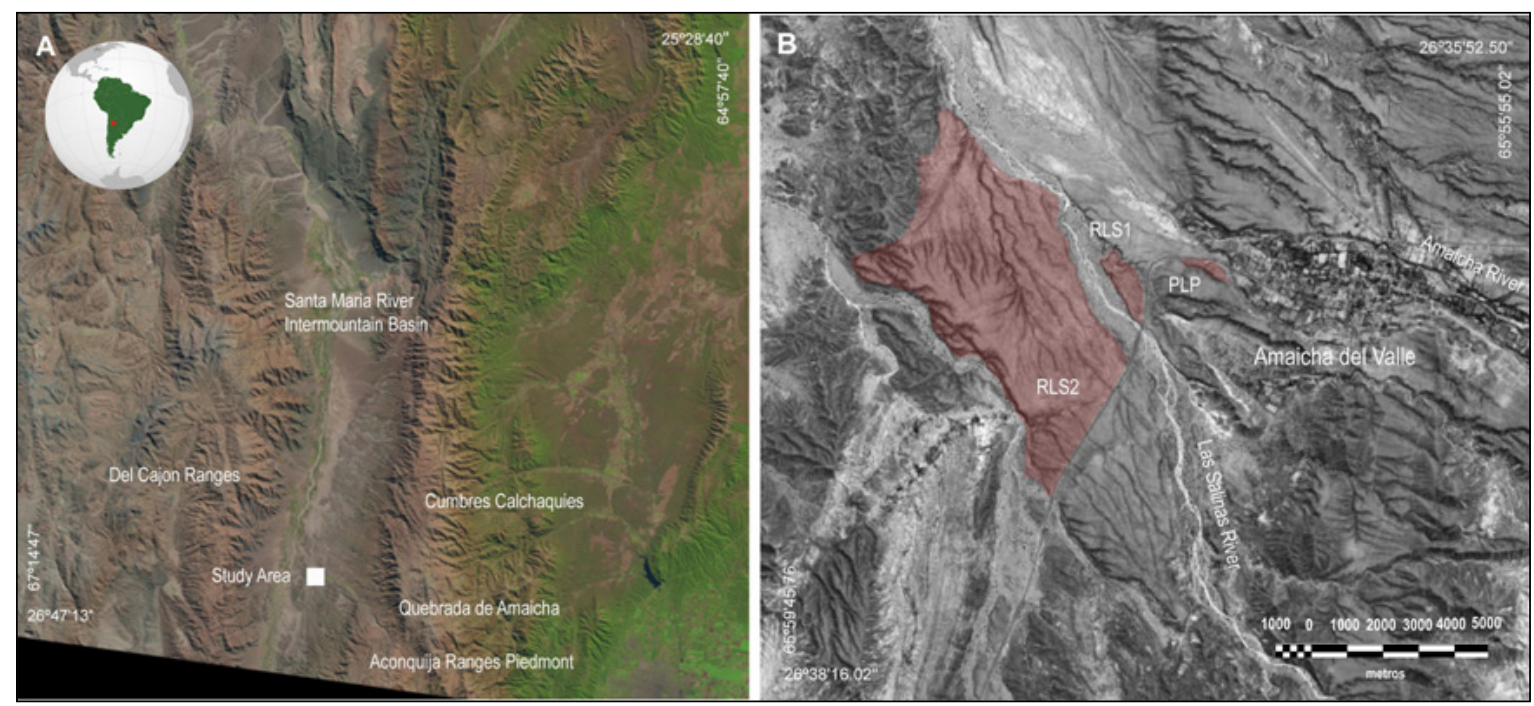

Figura 1A. Localización del área de estudio.

Figura 1B. Ubicación de las superficies de glacis.

de sedimentos hacia los cauces. La retroalimentación entre erosión hídrica y eólica ha potenciado el impacto de las precipitaciones sobre el paisaje, contribuyendo prácticamente a la desaparición del primitivo suelo, el cual solo se conserva como remanente, enterrado en pedestales que soportan la vegetación actual, espacialmente heterogénea (Collantes y González 2012; Sayago et al. 2012; Gómez Augier y Caria 2012). En el área coexisten elementos de las provincias fitogeográficas del Monte y Prepuna (Perea 1995). Así, pueden encontrarse especies arbóreas, como algarrobos (Prosopis alba y Prosopis nigra), churquis (Acacia caven), arcas (Acacia visco), chañares (Geoffroea decorticans); breas (Cercidium praecox). Arbustos como Bulnesia sp.; Monthea aphylla, jarillales de Larrea cuneifolia y Larrea divaricata. Cactáceas como los cardones (Trichocereus atacamensis y Opuntia sulphuria); especies de zonas inundadas o ribereñas, como pajonales formados por totoras (Typha latifolia) y juncales (Juncus sp.) (Collantes y González 2012).

\section{Unidad de análisis: superficie de glacis Río Las Sa- linas 2 (RLS2)}

La superficie de glacis Río Las Salinas se ubica en el sector medio de la quebrada de Amaicha. RLS2 forma parte de una superficie de glacis mayor que se encuentra disectada hacia el este por el cauce y llanura de inundación del río
Las Salinas, hacia el sur por la Ruta Provincial 307 (Tucumán, Argentina) y hacia el oeste por el río La Paloma. Esto hace que la misma superficie de glacis esté separada en sectores a los que hemos denominado arbitrariamente Río Las Salinas 1 (RLS1 a $1903 \mathrm{msnm}, 26^{\circ} 35^{\prime} 17.27^{\prime \prime}$ S y $65^{\circ} 57^{\prime} 8.14^{\prime \prime}$ O); Río Las Salinas 2 (RLS 2 a 1885 msnm, $26^{\circ} 35^{\prime} 12.46^{\prime \prime} \mathrm{S}, 65^{\circ} 57^{\prime} 42.99^{\prime \prime}$ O) y Planchada La Puntilla (PLP a 1990 msm, $26^{\circ} 35^{\prime} 49^{\prime \prime}$ S, 65 56' 97" O) (Figura $1 \mathrm{~B}$ ). Sobre las superficies de estos glacis, es común la presencia de pavimentos (o pedregosidad), uno de los procesos geomorfológicos del área, cuya relevancia arqueológica es tratada en este trabajo. En términos generales, los pavimentos son vistos como espacios apropiados para el abordaje de la estabilidad de los conjuntos artefactuales, en el largo plazo (Barton 2003; Matmon et al. 2009; Aldersberger y Smith 2009; Aldersberger et al. 2013). Por definición, están caracterizados por una capa superficial de clastos gruesos que recubren unidades de sedimento fino (Aldersberger y Smith 2009). En Amaicha del Valle, la cobertura de estos pavimentos consiste en clastos volcánicos angulares y subredondeados, fundamentalmente de andesitas y basaltos, y en menor proporción cuarzos y rocas metamórficas, que recubren un sedimento arenoso. Estos pavimentos ocupan la división topográfica generada por canales por los cuales circula el agua en la época estival, en sentido SE-NO y que disectan internamente el paisaje. 
A pesar de la estabilidad asociada a los pavimentos, las superficies de los mismos no son estáticas (Aldersberger et al. 2013). Las características específicas de los pavimentos son descriptas a través de mediciones de los clastos que forman parte de la cobertura clástica que recubre una superficie determinada. Estas mediciones brindan información sobre la madurez, antigüedad y grado de deterioro de los pavimentos, junto con la forma de dichos clastos. La madurez del pavimento se exhibe principalmente por la mayor cobertura de clastos sobre la superficie del suelo. Una vez concentrado el material grueso en la superficie de un suelo desértico, los procesos de intemperización, típicos de estos ambientes, rompen las rocas en fragmentos cada vez más pequeños. Donde menor sea el tamaño de los clastos y mayor sea la cobertura del pavimento por clastos pequeños, mayor grado de deterioro presentará el pavimento y, en consecuencia, más maduro será (Aldersberger y Smith 2009). Una de las propiedades que ayudan a definir el grado de deterioro de un pavimento es la litología de los clastos, ya que hay composiciones de las rocas más susceptibles a ser afectadas por procesos de meteorización y, por ende, a romperse más rápidamente en pedazos más pequeños (Aldersberger y Smith 2009). Además, definen el grado de preservación de los pavimentos la cobertura vegetal y la bioturbación (Quade 2001). En el área de estudio se están realizando trabajos exhaustivos para obtener información respecto a la madurez del pavimento. En este trabajo se presentan sus resultados preliminares.

El registro arqueológico en RLS2 (al igual que en RLS1 y PLP) se caracteriza por el predominio de material arqueológico lítico de superficie, afectado por barniz de las rocas, que se manifiesta bajo diversas modalidades: artefactos líticos tallados (núcleos, desechos de talla, artefactos formatizados), arte rupestre y estructuras (recintos, alineaciones y 'amontonamientos' de piedra que manifiestan cierta variabilidad en cuanto a sus dimensiones). Estos componentes se presentan en superficie y son difíciles de definir. Sin embargo, pueden identificarse a partir de las características geomorfológicas, dentro de la misma superficie de glacis y en asociación a los pavimentos mejor preservados.

El barniz que recubre el registro lítico en RLS2, RLS1 y PLP fue datado mediante VML (varnish microlamination). La premisa básica del VML es que la formación de mi- crolaminaciones en el barniz se encuentra fuertemente afectada por las variaciones climáticas locales y regionales (Liu y Broecker 2007). Debido a que las variaciones climáticas registradas en el barniz son regionalmente contemporáneas, el VML puede ser usado como una herramienta de datación correlativa que brinda edades mínimas de exposición de las superficies geomorfológicas que poseen barniz en áreas desérticas y semidesérticas (Liu y Broecker 2007; 2008a, b). En Amaicha del Valle, las primeras dataciones brindaron una edad mínima de exposición de los artefactos de, al menos, 6500-5900 años AP y de las superficies de 7300 años AP (Somonte y Baied 2013). Estas dataciones sirvieron, además, para establecer variaciones climáticas pasadas. Se detectaron ocho eventos húmedos durante el Holoceno, los cuales tuvieron lugar entre $7300 \mathrm{AP}$ y $300 \mathrm{AP}$ (Somonte y Collantes 2007; Collantes y Somonte 2007; Baied y Somonte 2013). Algunos de estos eventos húmedos han encontrado un correlato con otras fuentes paleoambientales, como los paleosuelos (Collantes y González 2012).

Hemos planteado en trabajos anteriores que las evidencias de reclamación arquitectónica y artefactual (Somonte y Baied 2010, Baied y Somonte 2011; Adris 2012) y los diferentes momentos de ejecución en las representaciones rupestres (Adris 2013), ponen de manifiesto la reocupación de estos amplios espacios a lo largo del tiempo. Si bien desde las dataciones de VML no se pueden establecer precisiones cronológicas respecto a estas reocupaciones, desde el análisis de las series cronológicas de las manifestaciones rupestres, hemos podido apreciar, por lo menos, cinco momentos de ejecución de las representaciones que podrían vincularse con diferentes lapsos temporales de ocupación (Adris 2013). Desde un aspecto funcional, consideramos que el uso de espacios como RLS2 estuvo destinado al aprovisionamiento de materias primas líticas bajo formas diversas y la manufactura de diferentes instrumentos. El uso de algunos de ellos se relacionó con la explotación de recursos particulares como la madera (Somonte y Baied 2013; Germano 2016). Este recurso fue reconocido por los grupos locales como parte de un espacio de retorno previsto y, por lo tanto, recurrentemente utilizado (sensu Somonte 2007). En este sentido, ambos recursos críticos - materias primas líticas y madera- para las estrategias de subsistencia de grupos cazadores recolectores fueron marcados o denotados mediante las representaciones rupestres (Adris 2013). 


\section{* Metodología}

\section{Escala del paisaje}

En RLS2 prospectamos, de manera pedestre, la totalidad de la superficie del glacis $(8.30 \mathrm{~km} 2)$. Durante la prospección registramos en una ficha específica información relacionada con elementos del paisaje sobre la dinámica de la erosión hídrica y eólica, la cobertura vegetal, la bioturbación y el riesgo erosivo. Entre estos elementos tuvimos en cuenta: pendiente, características del sedimento, propiedades del pavimento (textura y granulometría de los componentes rocosos, presencia de endurecimiento de los suelos), características de surcos y cárcavas, distribución y composición de la cobertura vegetal, descripción de pedestales, acción de roedores y pisoteo de animales. Los resultados de esta prospección sirvieron, a su vez, para definir áreas más reducidas dentro del glacis que, a su vez, fueron prospectadas más intensamente. Sobre estas áreas se realizaron muestreos sistemáticos, entendidos como una técnica estadísticamente válida que permite realizar predicciones respecto a la densidad total de recursos, distribución y variabilidad. El diseño de muestreo consistió en una combinación de transectas implementadas para maximizar la inspección intensiva de zonas difíciles para el registro de ciertos rasgos. Se trazaron cinco transectas paralelas de $5 \mathrm{~m}$ de ancho cada una (25 m en total) y una longitud de $1300 \mathrm{~m}$, donde se incluyeron una variabilidad de espacios, con mayor y menor dinamismo geomorfológico, de manera que obtuvimos la representatividad de una amplia gama de situaciones en las que tuvieron lugar los procesos geomorfológicos y posdepositacionales (Baied y Somonte 2013). El área recorrida intensamente abarcó una superficie de 3,25 ha (Figura 2).

A esta información sumamos los datos disponibles para el valle de Santa María sobre cobertura vegetal y riesgo erosivo (Sayago et al. 2012; Collantes y González 2012). Estos autores calcularon la cobertura vegetal basados en el porcentaje de canopia y mantillo en las estaciones húmeda y seca y, el riesgo erosivo a partir del cálculo del factor ' $C$ ' o Ecuación Universal de Pérdida de Suelo (sensu Wischemeir y Smith 1978).

\section{Escala de los artefactos}

En RLS2, la recolección de artefactos líticos se realizó durante el recorrido de las transectas mencionadas anteriormente. La recolección puntual de los materiales se realizó cada vez que aparecieron artefactos líticos, independientemente de la densidad. Estos espacios, donde se focalizó la recolección, fueron definidos como microsectores y cuyas dimensiones son de entre $1 \mathrm{~m} 2$ y $2 \mathrm{~m} 2$ cada uno. Los conjuntos líticos recolectados fueron embolsados y etiquetados por microsector de manera que quedara consignada la procedencia de cada uno.

En el laboratorio tuvimos en consideración las alteraciones posdepositacionales que afectan a las caras de las piezas líticas en general. En este trabajo, las pátinas (rock coatings) son entendidas como sedimentos geoquímicos que afectan a las superficies de las rocas (Dorn 2007). Se tuvieron en cuenta: 1) barniz de las rocas; 2) iron film $y$, 3) calcretes. Para entender las implicancias arqueológicas de las alteraciones posdepositacionales es necesario comprender los procesos por los cuales se forman, así como los tiempos involucrados en cada caso.

El barniz de las rocas es una pátina oscura, rica en manganeso y hierro, producto de un lento proceso acrecional que recubre las rocas expuestas en superficie en diversas geoformas de ambientes áridos y semiáridos (Liu y Broecker 2007) (Figura 3A). El barniz es considerado el proceso sedimentario más lento del mundo ( $<1$ a $40 \mathrm{ctm}$ cada mil años) (Liu y Broecker 2007, 2000) y constituye una herramienta geocronológica que informa acerca del paso del tiempo. Esta pátina es un indicador de estabilidad de ciertas georformas, cuyo análisis permite evaluar -entre otros aspectos-, el pool de variación de dicha estabilidad (Somonte y Baied 2013). El barniz requiere para su desarrollo -entre otras cosas- de la exposición de la superficie de la roca debido a que, en tanto es resultado de un proceso acrecional, se forma exclusivamente sobre materiales que están expuestos en superficie (Somonte y Baied 2010, 2013). Esta pátina no se desarrolla como una capa uniforme, sino que se origina en depresiones o grietas de la roca y luego se expande en todas direcciones. Esto ocurre a partir de un 'centro nuclear' de la roca que posee superficies relativamente ásperas, como es el caso de basaltos y andesitas, que permiten un rápido desarrollo de los barnices (Dorn y Oberlander 1982; 


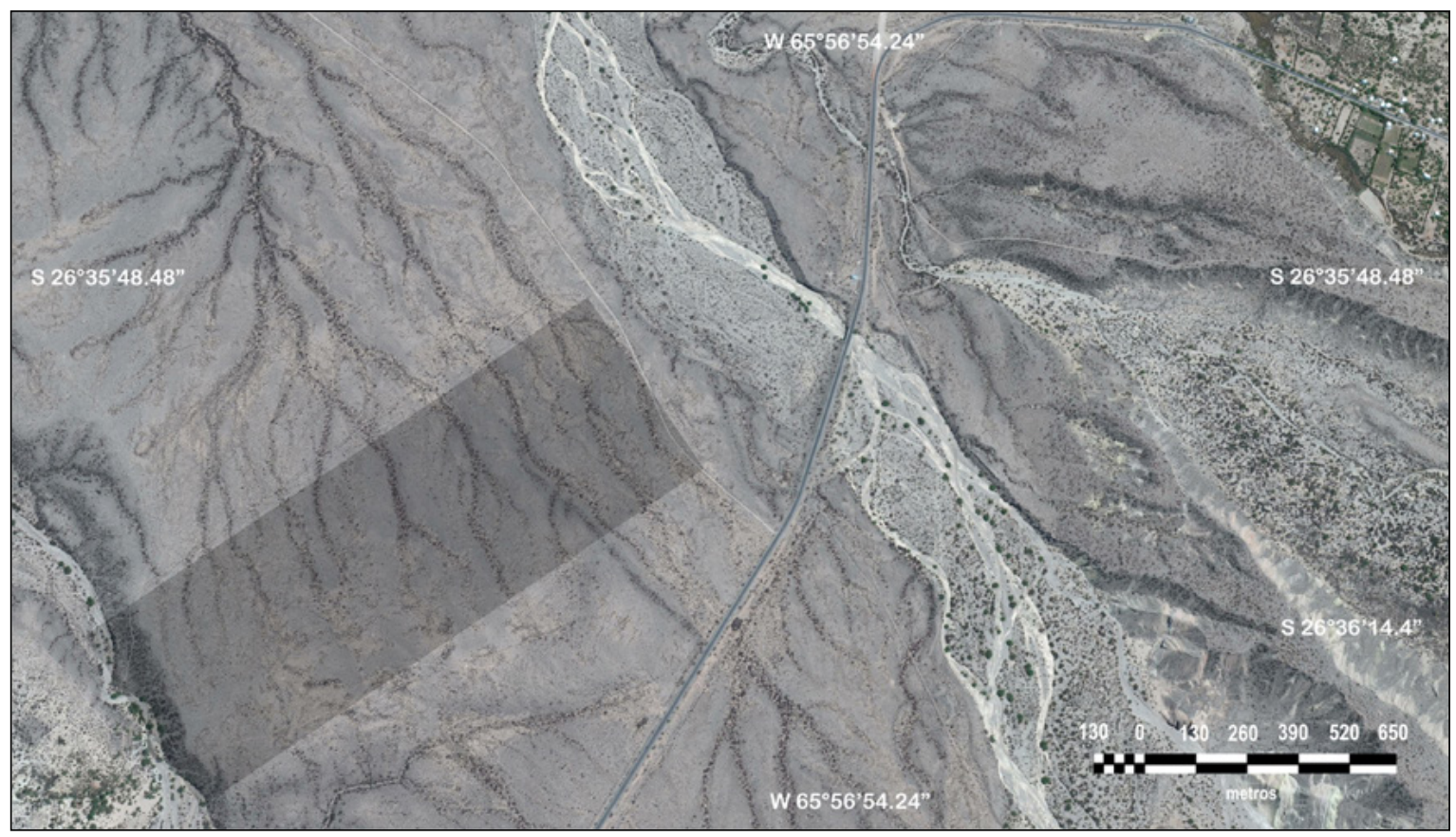

Figura 2. Área de recolección en RLS2.

Oberlander 1994). Las superficies rugosas poseen diminutas depresiones que retienen la humedad por largos períodos y actúan como 'trampas' para las partículas que son transportadas por el viento, manteniendo un medio ambiente óptimo para el 'crecimiento' del barniz (Schneider y Bierman 1997).

En segundo lugar, la pátina iron film se forma en la cara opuesta al sector donde se desarrolla el barniz, en la cara que asienta sobre el sustrato. Se trata de una película fina compuesta de minerales arcillosos y hierro. El color de esta pátina es beige, aunque a veces puede ser anaranjado, en función del grado de desarrollo de la misma (Figura 3B). Este iron film es resultado del contacto de la superficie de las piezas líticas y el sustrato e incluye la incorporación de componentes minerales del suelo a la superficie de la roca. Esto implica que existe una relación entre la composición química de esta pátina y la del sustrato subyacente. La importancia de esta pátina radica en que su formación involucra, al igual que el barniz, ciertas condiciones de estabilidad y tiempo para su desarrollo. La distribución del barniz de las rocas y el iron film en una y otra cara de los artefactos, respectivamente, refleja una condición de estabilidad de la geoforma en la que yacen estos litos. La existencia de ambas alteraciones advierte momentos durante los cuales los procesos geomorfológicos no han actuado intensamente como para evitar el desarrollo de estas pátinas. La asociación del barniz de las rocas con el iron film (en caras opuestas de una misma pieza) es un elemento común en ambientes áridos o semiáridos con pavimento del desierto (Dorn 2009).

En tercer lugar, las costras carbonáticas o calcretes $\left(\mathrm{CaCO}_{3}\right)$ son producto de la disolución de carbonatos en el agua de la napa freática, la que al fluctuar hace que los carbonatos precipiten, afectando los clastos depositados en numerosas geoformas (García Salemi y Durando 1985; García Salemi et al. 1988). Se trata de una película de distintos espesores que recubre los artefactos líticos y cerámicos, pudiendo ser retirada al lavarse con agua destilada mezclada con una solución de ácido clorhídrico al $10 \%$. Esto quiere decir que no hay una incorporación de esta costra a la superficie del material -sea este lítico o cerámico- sino que se trata de un elemento externo $y$, en mayor o menor medida, removible (Figura $3 \mathrm{C}$ ). En los casos en que los calcretes aparecen asociados al barniz de las rocas o al iron film se presentan cubriendo estas dos pátinas, lo que significa una formación posterior. El calcrete es común entre los materiales localizados en subsuperficie y no así entre los que están en superficie. 

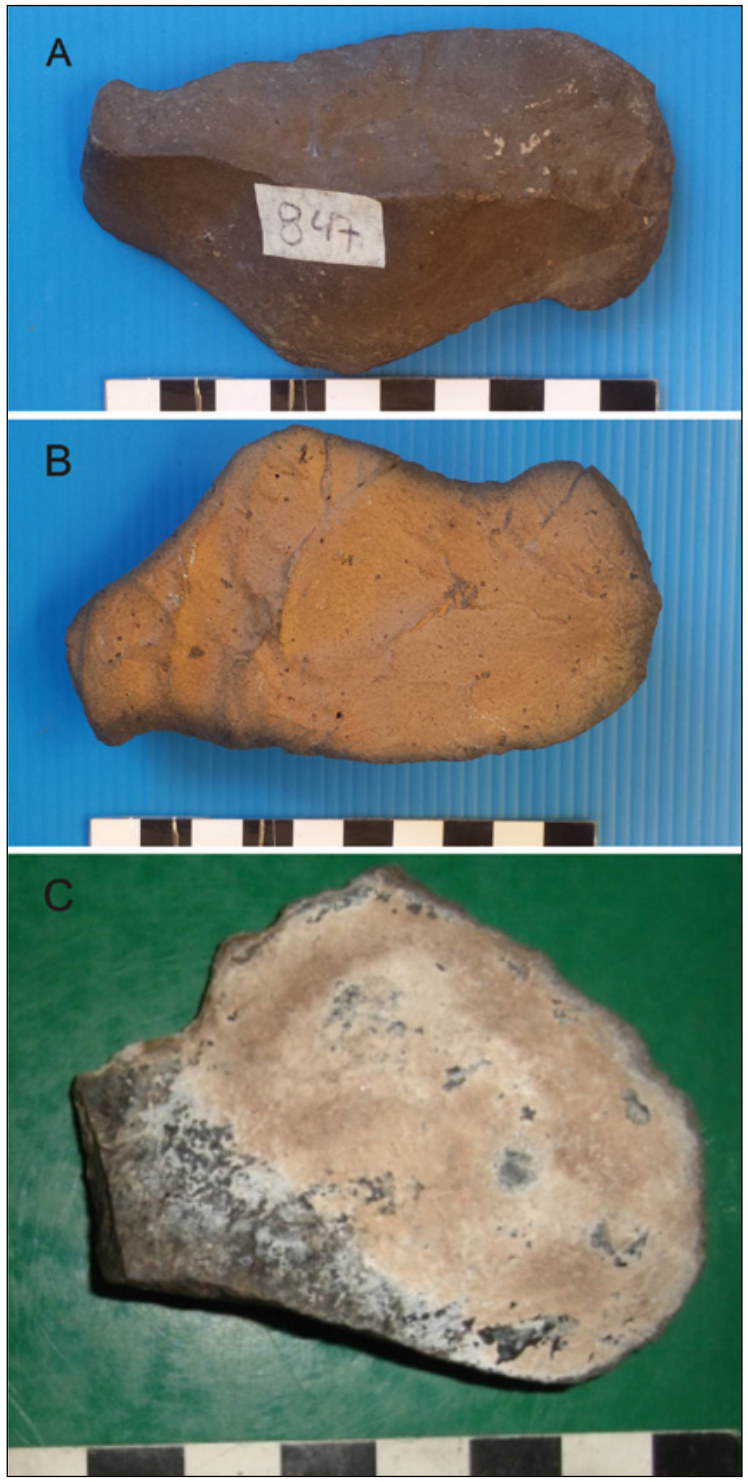

Figura 3. Alteraciones posdepositacionales.

3.A. Barniz de las rocas, 3.B. Iron film, 3.C. Calcretes.

Otro aspecto que tuvimos en cuenta en los trabajos de laboratorio fue el grado de abrasión de las piezas, entendido como un indicador importante de exposición aérea y por tanto útil a la hora de discutir grados de exposición diferencial de los conjuntos líticos a la erosión eólica e hídrica. Tomamos en cuenta la propuesta de Hiscock (1985) y las modificaciones de Borrazzo (2006), aunque con agregados en la terminología involucrada en la definición de cada categoría o estadio de abrasión:
Estadio o: Fresca. Las aristas y superficies de negativos/positivos de lascados son homogéneas en toda la pieza. No se registra abrasión. La textura y el brillo natural de la roca no tienen modificación alguna.

Estadio 1: Levemente abradido. Si bien las aristas se presentan redondeadas, todavía se distinguen los atributos diagnósticos de los negativos/positivos de lascados (estrías, ondas, etc.). La abrasión en estos casos no llega a modificar sustancialmente la textura y brillo natural de la roca. 
Estadio 2: Abradido. Las aristas se presentan redondeadas y los atributos diagnósticos de las superficies de negativos/positivos de lascados han desaparecido parcialmente, siendo dificultosa su identificación. En estos casos, la textura es algo áspera al tacto y aumenta su opacidad.

Estadio 3: Muy abradido. Las aristas y todos los atributos diagnósticos de las superficies de lascado han desaparecido completamente. En estos casos la textura es áspera al tacto y luce totalmente opaca a la vista. Incluso, la roca adquiere una apariencia porosa.

Finalmente, las tareas de ensamblaje se realizaron sobre los materiales agrupados, fundamentalmente, de acuerdo al microsector de procedencia y la materia prima. Los conjuntos líticos fueron analizados tipológicamente siguiendo las propuestas de Aschero (1975, rev. 1983) y Aschero y Hocsman (2004). Para la realización de las tareas de ensamblaje consideramos las siguientes variables: planos o superficies de fractura; presencia/ausencia de atributos tipológicos de las caras ventrales (punto de percusión, ondas y estrías) y dimensiones relativas y absolutas de las piezas. Además, se tuvieron en cuenta las pátinas y su distribución en las caras y planos de fractura de los artefactos que se ensamblaron, lo que permitió evaluar aspectos temporales relativos a los eventos de talla in situ, así como también posibilitaron el establecimiento de una secuencia temporal de las fracturas presentes en cada artefacto.

\section{$\because$ Resultados}

Los resultados se organizaron en función de las escalas: paisaje y artefacto. Con respecto al paisaje, se presentan los resultados de los principales procesos geomorfológicos resultantes de aspectos como la cobertura vegetal, la erosion hídrica y eólica, el riesgo erosivo, la bioturbación y las características de los pavimentos. Con respecto al artefacto se presentan los resultados de los análisis tipológicos, las alteraciones posdepositacionales y su distribución, los grados de abrasión y las tareas de ensamblaje.

\section{El paisaje y los procesos geomorfológicos}

La cobertura vegetal posee una baja respuesta estacional, es decir que no hay una modificación sustancial en el paisaje a lo largo del año (Tabla 1). La vegetación se encuentra concentrada, aunque no exclusivamente, sobre los canales de escorrentía natural como surcos y cárcavas. En estos sectores también se aprecia un aumento de la vegetación efímera (pasturas) durante el verano, indicando concentración de escorrentía durante la estación húmeda. En general, observamos que la escasez y espaciamiento de la vegetación es un factor importante que define la efectividad de la erosión eólica por deflación (Figura 4C). La presencia de materiales sueltos y secos en superficie, en conjunto, inciden negativamente ante un aumento de la velocidad del viento, intensificando el proceso de deterioro de los suelos (Collantes y González 2012). Esto último se relaciona con el riesgo erosivo. Su cálculo está basado en la capacidad de resiliencia de cada unidad de relieve de la ladera occidental de cumbres calchaquíes (Sayago et al. 2012). Estos autores sostienen que en el piedemonte distal (donde se encuentra RLS2) el riesgo erosivo es grave, lo que está avalado, en parte, por la mencionada baja respuesta estacional de la cobertura vegetal, que junto a la erosión eólica e hídrica contribuyen a la pérdida de suelo o factor 'C' (Sayago et al. 2012). Al respecto, las mediciones que realizaron Collantes y González (2012) sobre el cálculo del factor ' $\mathrm{C}$ ' coinciden con nuestras observaciones de campo. Las mismas indican que la superficie de los glacis presenta aproximadamente un $25 \%$ de cobertura vegetal, caracterizada por arbustos en pedestales (principalmente Larrea sp.). Éstos poseen un ancho promedio que puede variar entre 1,20 y $2,10 \mathrm{~m}$, con una separación variable entre ellos (inferior al metro o de casi 3 m) (Figura $4 \mathrm{E}$ ).

Entre los pedestales que contienen principalmente a la vegetación arbustiva, el horizonte "A" ha sido erosionado, mayormente por erosión hídrica y erosión eólica, originando en algunos casos vías de escurrimiento (surcos o cauces efímeros) y en otros una cobertura pedregosa de clastos o pavimento (Sayago et al. 2012). Los estudios de suelos efectuados en los pedestales permitieron evaluar la variabilidad climática en el valle de Santa María debido a que se detectó el desarrollo de un paleosuelo (A-C o A/ $\mathrm{AC}-\mathrm{C}$ ), cuya datación arrojó una edad de $435 \mathrm{ffl} 15 \mathrm{AP}$, obtenida mediante AMS (Acelerador de Partículas) (Collantes et al. 2011). Esta datación se corresponde con el último evento húmedo registrado mediante VML, el que tuvo lugar entre $650 \mathrm{AP}$ y $300 \mathrm{AP}$ (Somonte y Baied 2013). 


\begin{tabular}{|c|c|c|c|c|c|c|c|}
\hline $\begin{array}{c}\text { Unidad de } \\
\text { relieve } \\
\text { Piedemonte } \\
\text { distal }\end{array}$ & $\begin{array}{c}\text { Área } \\
\text { prospectada }\end{array}$ & Pendiente & $\begin{array}{c}\text { Cobertura vegetal } \\
\text { (\% de canopiay } \\
\text { mantillo) }\end{array}$ & Erosión hídrica & $\begin{array}{c}\text { Efectividad } \\
\text { erosión eólica } \\
\text { (deflación) }\end{array}$ & $\begin{array}{c}\text { Pavimento del } \\
\text { desierto }\end{array}$ & $\begin{array}{c}\text { Riesgo } \\
\text { erosivo } \\
\text { (Tn/Ha/año- } \\
\text { USLE) }\end{array}$ \\
\hline $\begin{array}{c}\text { Glacis Río Las } \\
\text { Salinas }\end{array}$ & $\begin{array}{c}8.30 \mathrm{~km} 2 \\
\text { (corresponde } \\
\text { a RLS 2) }\end{array}$ & $@ 1-5 \%$ & $\begin{array}{c}20 \% \text { estación seca } \\
40 \% \text { estación húmeda }\end{array}$ & $\begin{array}{c}\text { Predominio de la } \\
\text { erosión laminar }\end{array}$ & Mayor efectividad & Buen desarrollo & $29-47$ \\
\hline
\end{tabular}

Tabla 1. Síntesis de las principales características del paisaje en RLS2.

*Nota: Datos provenientes del valle de Santa María (Collantes y González 2012 y Sayago et al. 2012).

La bioturbación, específicamente el accionar de roedores y el pisoteo de animales, no tiene un accionar homogéneo en RLS2. En aquellos sectores más erosionados, registramos abundantes madrigueras de roedores, que afectan especialmente las áreas donde se concentra la vegetación y está ausente el pavimento del desierto. Por su parte, el efecto del pisoteo de animales, fundamentalmente burros (Equus asinus) es más evidente en los sectores con pavimento, provocando remoción y fractura de los artefactos y clastos localizados en la zona de tránsito de estos animales. Esto significa que donde tiene lugar la acción de los roedores, el efecto de pisoteo de animales no es tan relevante. Inversamente, donde tiene lugar la acción del pisoteo de animales, el efecto de los roedores es menos significativo.

En cuanto a las características de los pavimentos, la cobertura de clastos está compuesta de andesitas, basaltos $y$, en menor proporción, rocas metamórficas y cuarzos. Esta cobertura muestra diferencias en diversos sectores de acuerdo al tamaño, forma y densidad de los mismos que permiten diferenciar tres clases de cobertura vegetal. Por una parte, se registraron sectores cuyo pavimento cuenta con una cobertura alta que supera el $80 \%$ de clastos de forma angular y de tamaños que varían entre 5 y $12 \mathrm{~cm}$ (Figura $4 \mathrm{~B}$ y D); también se registraron clastos aislados de tamaños importantes, cercanos al metro. Los sectores que cuentan con un pavimento preservado están relacionados con espacios donde se concentran los conjuntos artefactuales líticos. Por otra parte, se registraron en otros sectores del espacio prospectado, una cobertura media, menos densa, cerca del 60\% de clastos de forma subredondeada y de un tamaño menor, que varía entre 2 y $5 \mathrm{~cm}$ (Figura 4A). Estos espacios cuentan con áreas disturbadas, por diferentes agentes erosivos $y$, en general, se encuentra material arqueológico aislado en algunos sectores de las superficies. En aquellas áreas, sumamen- te erosionadas que rodean a las superficies con estos pavimentos residuales, la cobertura de clastos es casi nula ( $\leq 10 \%)$ (Figura $4 \mathrm{C}$ ) y el material arqueológico está ausente. Estos dos tipos de paisajes amplios (áreas con pavimento afectado por pisoteo de animales, rodeado de espacios más bajos sin pavimento donde se concentra la vegetación y cuevas de roedores) permiten distinguir en el paisaje una suerte de mosaicos visualmente distintivos. Estos mosaicos superficiales varían de forma discreta y colindan entre sí, conformando límites relativamente precisos en muchos casos o a través de superficies transicionales.

\section{Artefactos líticos}

Caracterización tipológica de los conjuntos artefactuales. Los artefactos analizados provienen de las recolecciones realizadas en los microsectores de las transectas trazadas en RLS2. Se recolectaron un total de 469 piezas, de las cuales casi el 63\% (295) son desechos de talla; más del $20 \%$ (96) corresponden a artefactos formatizados; cerca del 9\% (41) se trata de núcleos y, finalmente, el 8\% restante (37) son filos naturales con rastros complementarios (Tabla 2). El conjunto instrumental unifacial $(n=73)$ registra una baja inversión de manufactura, teniendo en cuenta la serie técnica observada y el hecho de que los artefactos en general no están mantenidos. Las piezas tienen dimensiones variables entre 5-10 cm de longitud. Entre los artefactos bifaciales $(n=18)$, donde es mayor la inversión en su manufactura, en los grupos tipológicos se aprecia el predominio de bifaces $(n=12$, bifaces parciales en todos los casos); esbozos de piezas bifaciales $(n=4)$ y el resto son fragmentos de filos bifaciales de arista sinuosa. La mayoría de las piezas bifaciales superan los $10 \mathrm{~cm}$ de longitud. Los núcleos en general no responden a la búsqueda de formas base específicas, ya que se registra una importante variabilidad en cuanto a su designación 


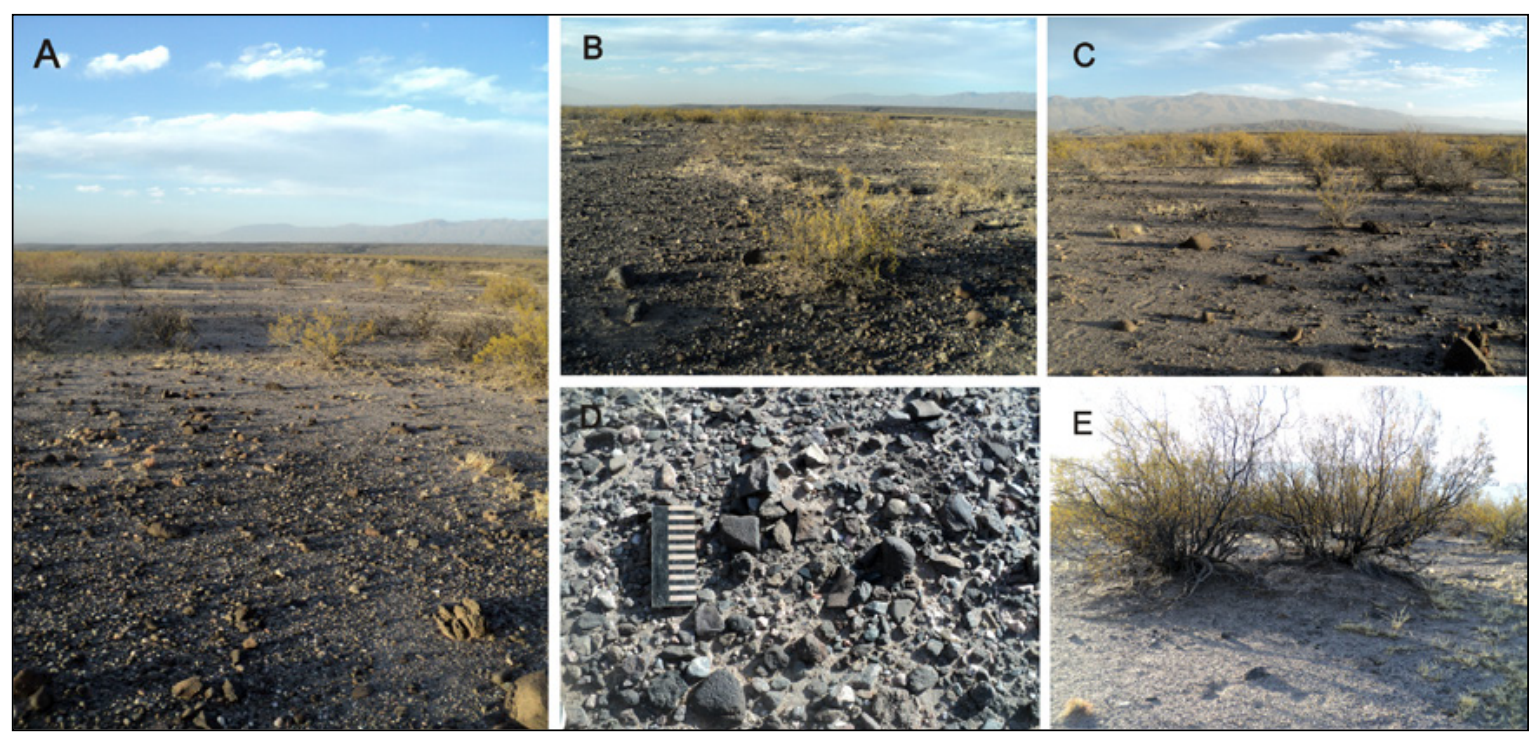

Figura 4. Diferentes grados de preservación del pavimento y detalle de pedestales en RLS2.

4.A. Pavimento con cobertura media. Nótese atrás de la imagen la superficie libre de pavimento.

4.B. Superficie con pavimento preservado, 4.C. Efectividad de la erosión eólica por deflación, 4.D. Detalle de la superficie con pavimento, 4.E. Detalle de los pedestales.

morfológica. Las dimensiones de los núcleos oscilan entre $10-40 \mathrm{~cm}$ de longitud. Los desechos de talla corresponden a etapas de reducción primaria y secundaria, lo cual evidencia la extracción de formas base y regularización de filos de instrumentos en RLS2. Las dimensiones de los desechos se encuentran entre los 2-10 cm de longitud. En cuanto a las materias primas en el conjunto, más del 90\% se trata de andesitas, un poco más del 8\% corresponde a cuarzo y menos del $2 \%$ restante se distribuye entre cuarcitas, sílices y recursos no diferenciados. Las andesitas y el cuarzo se encuentran disponibles en la misma superficie del glacis. Las fuentes de cuarcitas y sílices, si bien no fueron localizadas, se encuentran disponibles como vetas en el basamento de las sierras del Aconquija, a más de $20 \mathrm{~km}$ de distancia de RLS2. Las alteraciones posdepositacionales afectan diferencialmente a las materias primas, ${ }^{3}$ y son las andesitas (predominantes entre las materias primas) el tipo de roca más favorable para el desarrollo del barniz de las rocas y el iron film. Por tal motivo, los resultados del análisis de las pátinas, grados de abrasión y tareas de ensamblaje se centraron en el conjunto artefactual confeccionado en andesitas.

3 Entre las alteraciones que no forman parte de este trabajo, se destacan los líquenes presentes exclusivamente en el cuarzo.
Alteraciones posdepositacionales. En RLS2 predomina la formación del barniz de las rocas (casi el 80\%) y el iron film $\left(>_{70 \%)}\right.$ en detrimento de los calcretes $\left(<_{5 \%}\right)(\mathrm{Ta}-$ bla 3). Esto es lógico, teniendo en cuenta la naturaleza superficial del registro arqueológico (fundamentalmente lítico). La presencia de calcretes en las piezas en porcentajes mínimos denota su enterramiento (total o parcial) en algún momento previo a su recolección en superficie. Conjuntamente con las piezas afectadas por alguna de las alteraciones, también hay casos de artefactos que no poseen ninguna clase de asociación con estas pátinas, presentándose la materia prima 'fresca', (alrededor del 5\%). Esto marca la coexistencia de piezas o conjuntos artefactuales, en superficie, con historias posdepositacionales distintas.

Teniendo en cuenta que una relativa estabilidad de la geoforma es una condición requerida para la formación y desarrollo tanto del barniz como del iron film, por sus implicancias temporales, es necesario detallar la distribución de dichas pátinas en relación con las caras de las piezas. Esto nos permitió evaluar la existencia (o no) de pulsos de estabilidad a nivel del paisaje. Como apreciamos en la Tabla 4, es elevada la proporción de piezas que poseen barniz en una de sus caras e iron film en su cara opuesta, lo que advierte la existencia de momentos de 


\begin{tabular}{|c|c|c|c|c|c|c|c|c|c|c|}
\hline \multirow[t]{2}{*}{$\begin{array}{c}\text { Materia } \\
\text { Prima }\end{array}$} & \multicolumn{2}{|c|}{ Núcleos } & \multicolumn{2}{|c|}{$\begin{array}{c}\text { Desechos de } \\
\text { talla }\end{array}$} & \multicolumn{2}{|c|}{ FNRC } & \multicolumn{2}{|c|}{$\begin{array}{c}\text { Artefactos } \\
\text { formatizados }\end{array}$} & \multicolumn{2}{|c|}{$\begin{array}{c}\text { Total por } \\
\text { Materia Prima }\end{array}$} \\
\hline & $\mathrm{N}$ & $\%$ & $\mathrm{~N}$ & $\%$ & $\mathrm{~N}$ & $\%$ & $\mathrm{~N}$ & $\%$ & $\mathrm{~N}$ & $\%$ \\
\hline Andesita & 35 & 7.46 & 262 & 55.86 & 37 & 7.90 & 91 & 19.40 & 425 & 90.62 \\
\hline Cuarzo & 4 & 0.85 & 33 & 7.04 & - & - & 2 & 0.43 & 39 & 8.31 \\
\hline Cuarcita & 1 & 0.21 & - & - & - & - & 1 & 0.21 & 2 & 0.43 \\
\hline Sílice & 1 & 0.21 & - & - & - & - & - & - & 1 & 0.21 \\
\hline No diferenciada & - & - & - & - & - & - & 2 & 0.43 & 2 & 0.43 \\
\hline $\begin{array}{l}\text { Total por clase } \\
\text { tipológica }\end{array}$ & 41 & 8.73 & 295 & 62.90 & 37 & 7.90 & 96 & 20.47 & 469 & 100 \\
\hline
\end{tabular}

Tabla 2. Conjunto lítico procedente del área de recolección de RLS2.

FNRC $=$ Filos naturales con rastros complementarios.

cierta estabilidad durante los cuales fue factible el desarrollo de dichas pátinas. También observamos casos en los que ambas caras están patinadas, ya sea con barniz de las rocas o iron film, que sugiere la depositación y posterior movilización de las piezas. En términos generales, en estos casos en una de las caras la coloración del barniz se ve levemente atenuada por la presencia de iron film que recubre el barniz desarrollado originalmente. Asimismo, la cara opuesta cubierta por iron film se encuentra parcialmente cubierta por barniz con un desarrollo incipiente. Esto marca la rotación del artefacto en estos casos, sin embargo este cambio en la posición de la pieza estuvo precedido y sucedido por determinada condición de estabilidad, que posibilitó el desarrollo de tales pátinas.

Una tercera situación importante de comentar es la de las piezas en las que el barniz de las rocas fue registrado en ambas caras, pero se superpuso al iron film en una de ellas. En estos contextos, en una de las caras se manifiesta el barniz de manera más intensa (predominando el color Munsell 7.5 $\mathrm{YR}_{3} / 1$ ) y en la otra posee un desarrollo incipiente (prevaleciendo el 7.5YR4/2), localizado generalmente sobre los bordes. Esta ubicación marginal del barniz está relacionada con sectores que pudieron no haber apoyado de manera efectiva sobre el sustrato (impidiendo el desarrollo del iron film en la totalidad de la superficie), sumado al crecimiento de naturaleza expansiva que caracteriza al barniz de las rocas (Dorn 1983; Reneau y Raymond 1991; Reneau et al. 1992). Un aspecto interesante del barniz es su presencia en los planos o super- ficies de fractura de los artefactos. Esta situación ofrece la posibilidad de establecer una secuencia temporal en la que se suceden $\mathrm{l} / \mathrm{s}$ fractura/s en una pieza. En numerosos casos el barniz se registró cubriendo (además de las caras) los planos de fracturas de diversos artefactos, lo que marca el importante lapso temporal transcurrido desde que esa fractura se produjo.

Abrasión de los artefactos. Los resultados del análisis de la abrasión presentada en la muestra indican que se manifiesta en grados diferenciales. Por un lado, notamos que un elevado porcentaje de las piezas no presenta abrasión alguna (casi el 60\%); mientras que por otro, cerca del $40 \%$ sí la registra, aunque en distintos estadios de intensidad (Tabla 5). Entre las piezas abradidas $(\mathrm{n}=192)$, $>_{70 \%}$ corresponde al estadio 2 (abradido); casi el 15\% al estadio 3 (muy abradido) y el 15\% restante al estadio 1 (levemente abradido). Esta variabilidad en los grados de abrasión la registramos, también, dentro de una misma pieza. En estos casos, están asociadas a distintos negativos de lascados, donde los más recientes no poseen abrasión alguna; mientras que los más antiguos se corresponden con alguno de los estadios de abrasión más intensos ( 2 o 3). Esto permite inferir, en el caso de los núcleos, la secuencia lógica de extracción durante las tareas de talla, pero además, procesos de reclamación, aun en ocasiones donde el barniz no es de ayuda, por estar levemente 'levantado' o borrado' como consecuencia de la abrasión. En tal sentido, la abrasión se convierte en una herramienta alternativa al barniz para evaluar numerosos 


\begin{tabular}{|c|c|c|c|}
\hline Alteraciones & Barniz delas rocas & Iron film & Calcretes \\
\hline Posee & $365(77.83 \%)$ & $334(71.22 \%)$ & $23(4.90 \%)$ \\
\hline No posee & $77(16.42 \%)$ & $107(22.81 \%)$ & $422(89.98 \%)$ \\
\hline No diferenciado & $4(0.85 \%)$ & $5(1.07 \%)$ & - \\
\hline No corresponde* & $23(4.90 \%)$ & $23(4.90 \%)$ & $24(5.12 \%)$ \\
\hline
\end{tabular}

Tabla 3. Distribución de las alteraciones en la muestra de RLS2 $(N=469)$.

*Incluye piezas confeccionadas en materias primas sobre las que no se forman las pátinas tratadas en este trabajo (cuarzo y sílice).

\begin{tabular}{|c|c|c|}
\hline Distribución en las caras de las piezas & Barniz de las rocas & Iron film \\
\hline Una de las caras & $298(81.65 \%)$ & $23(6.89 \%)$ \\
\hline Cara opuesta & - & $268(80.24 \%)$ \\
\hline Ambas caras & $61(16.71 \%)$ & $43(12.87 \%)$ \\
\hline Sector marginal de la pieza & $6(1.64 \%)$ & - \\
\hline Total por pátina & $365(100 \%)$ & $334(100 \%)$ \\
\hline
\end{tabular}

Tabla 4. Distribución de las alteraciones postdepositacionales en las caras de las piezas.

procesos de formación naturales y culturales, entre estos últimos, los de reclamación. La abrasión repercute negativamente en las posibilidades de datar el barniz de las rocas mediante VML, ya que la exfoliación de la superficie de la pieza involucra la mayoría de las veces el barniz, borrando y deteriorando su microestratigrafía, crucial para la aplicación de la técnica (Somonte y Baied 2013).

Por otra parte, al evaluar la posición de la abrasión con respecto a las caras de las piezas, se observa que casi un $90 \%$ de ellas están abradidas solo en una de sus caras. A su vez, un número importante de estos casos corresponde a una abrasión vinculada a los negativos de lascados más antiguos, correspondientes a las primeras extracciones de la secuencia lógica de producción. Esto denota, además de la reclamación, ciertas condiciones de estabilidad durante el tiempo que las piezas estuvieron depositadas en la superficie, lo que, simultáneamente, se ve reforzado por el porcentaje mínimo de piezas (inferior al $10 \%)$ que registran abrasión en ambas caras, que estaría indicando situaciones de menor estabilidad paisajística.

Tareas de remontaje y reparación. Las tareas de remontaje involucraron el análisis de los materiales por materia prima y por unidad de recolección, de manera que hubo un control del grado de asociación de los conjuntos analizados. Se han detectado situaciones claras de ensamblajes tanto en el campo (dentro y fuera del área de recolección) como en los trabajos de laboratorio posteriores. Es necesario aclarar que se registraron situaciones de fracturas naturales, provocadas por estrés térmico y bioturbación que en este trabajo no fueron tenidas en cuenta para la evaluación de eventos de talla. En estos casos, las superficies que ensamblan no presentan ningún atributo diagnóstico de la talla intencional.

Dentro del área de recolección se ha recuperado parte de un evento de talla conformado por cuatro desechos de talla que vuelven a montar en un núcleo siguiendo una secuencia lógica de extracción. Además, la distribución del barniz en estas lascas (dos tienen barniz y las otras dos no) marca que la reducción del núcleo se produjo en momentos diferentes (Tabla 6). En el campo hemos observado eventos de talla in situ, que no han sido recolectados, pero sí registrados y localizados para análisis futuros. ${ }^{4}$ Esto quiere decir que, independientemente del

4 A esto se suman las tareas de laboratorio -en proceso- sobre materiales que, por sus características, podrían ser remontados o reparados, pero que no han sido considerados entre los resultados que aquí se presentan. Estas tareas específicas requieren paciencia y dedicación, lo que dificulta obtener resultados en el corto plazo. Sin embargo, de manera preliminar, se puede decir que los espacios con evidencia de talla in situ claramente son más numerosos que lo comentado en esta oportunidad. 


\begin{tabular}{|c|c|}
\hline Categoría de abrasión & \\
\hline Estadio o & $276(58.85 \%)$ \\
\hline Estadio 1 & $28(5.97 \%)$ \\
\hline Estadio 2 & $137(29.21 \%)$ \\
\hline Estadio 3 & $27(5.76 \%)$ \\
\hline No diferenciada & $1(0.21 \%)$ \\
\hline Total & $469(100 \%)$ \\
\hline
\end{tabular}

Tabla 5. Distribución de las categorías de abrasión entre las piezas líticas de RLS2.

número de casos presentados aquí, existen muchas situaciones similares en RLS2 que evidencian talla in situ que, en conjunto, ratifican la estabilidad de esta geoforma en determinados momentos, con posterioridad a la depositación original de los conjuntos tallados. En términos generales, estos talleres en RLS2 están asociados a sectores del pavimento que cuentan con cierto grado de preservación.

En segundo lugar, hemos recuperado desechos de talla que se unen siguiendo un plano o superficie de fractura, es decir, donde ambas partes pudieron ser reparadas. Esto se apreció en dos conjuntos de lascas diferentes en las que cuatro desechos pudieron ser reparados, convirtiéndose en realidad en dos. Es interesante el hecho de que en uno de los casos mencionados, el plano de fractura está cubierto por barniz, lo que marca el tiempo transcurrido desde la fractura del desecho (en dos piezas), sumado a la preservación de la asociación de estos materiales, que permitió su ensamblaje.

Finalmente, también registramos grupos de desechos relacionados a un mismo evento de talla, pero cuyas tareas de remontaje fueron imposibles dada la ausencia del núcleo. En estos casos, las características de la cara dorsal de las lascas como la corteza, el grado de abrasión de las aristas, el grado de desarrollo de las pátinas, entre otras, brindaron información relevante acerca de la relación entre estos desechos de talla, a pesar de la ausencia del núcleo. Se han identificado ocho eventos de talla diferentes, dispersos en el área de recolección, compuestos por conjuntos de lascas (en números variables de entre 5 y 11), pero cuyo núcleo estaba ausente. Si bien, en estos casos, las tareas de remontaje no fueron posibles, para los fines de este trabajo se considera igualmente relevante su mención dada la relación de los desechos con un mismo núcleo, y por lo tanto, a un mismo evento de talla. Tanto las situaciones de remontaje y reparación (uniones de superficies de talla o fractura), como los conjuntos de lascas asociados entre sí en el espacio, vinculados a un mismo evento de talla (a pesar de estar ausente el núcleo), en conjunto, favorecen la idea de estos pulsos de estabilidad que se vienen sosteniendo desde las diversas líneas de evidencia, a escala de paisaje y de artefacto. Sobre estos temas desarrollamos la discusión que sigue.

\section{Discusión de los resultados}

\section{Integrando escalas: del paisaje al artefacto y viceversa}

En RLS2 hemos trabajado a escala del paisaje y del artefacto (y viceversa) como parte de un juego continuo que pretendió dar cuenta de la dinámica geomorfológica de los espacios donde se encuentra el registro arqueológico. Este cambio de escalas es lo que posibilitó evaluar condiciones de estabilidad a nivel del paisaje y del artefacto. Particularmente fue la escala del artefacto la que, a su vez, permitió detectar situaciones de pulsos de estabilidad, que no pudieron ser establecidas a nivel del paisaje debido a la dinámica actual de los procesos que operan en el glacis. Asimismo, la escala del paisaje fue la que permitió establecer diferencias en las condiciones de preservación del pavimento. En este sentido, el uso de ambas escalas, y no solamente de una, fue importante a la hora de evaluar la variabilidad enmascarada dentro de una condición de estabilidad, que resultaron ser varias y no una sola. La estabilidad es un concepto comúnmente utilizado en Arqueología para aludir a la exposición de materiales óseos o líticos a determinadas condiciones durante un lapso prolongado. A esta idea acompaña la premisa de que lo que se ve en el artefacto es reflejo de lo que ocurre en el paisaje. Si bien esto podría ser así, compartimos con Borrero (2006) que los factores naturales locales pueden incidir de manera variable sobre 


\begin{tabular}{|c|c|c|}
\hline Remontaje núcleos/lascas & Núcleo poliédrico & Barniz de las rocas \\
\hline $5^{\circ}$ extracción & Lasca angular & No posee \\
\hline $4^{\circ}$ extracción & Lasca angular & Nosee \\
\hline $3^{\circ}$ extracción & Lasca angular $-7.5 \mathrm{YR}_{3} / 1$ \\
\hline $2^{\circ}$ extracción ausente & - & - \\
\hline $1^{\circ}$ extracción & Lasca angular & Si posee $-5 \mathrm{YR}_{3} / 2$ \\
\hline
\end{tabular}

Tabla 6. Detalle del remontaje por unión de superficies de lascados entre un núcleo y lascas.

el registro y que "this variability clearly shows that regional taphonomic processes do not necessarily produce a standard set of changes" (2006: 223). En este trabajo mostramos la variabilidad existente en los procesos tafonómicos a escala del paisaje y del artefacto y sostenemos que una variación en la escala enriquece la interpretación del registro arqueológico y, por lo tanto, de su historia de vida. Esto se ha traducido en el reconocimiento en el paisaje de condiciones de mayor y menor estabilidad que han permitido identificar en las superficies de glacis, pavimentos con distintos grados de madurez/deterioro.

RLS2 es producto de un conjunto de eventos de erosión (en mayor medida) y depositación (en menor medida) que operaron, y aún lo hacen, a diversas escalas temporales y espaciales. Su accionar a lo largo de los años ha dejado marcas en el paisaje que hoy se exhiben en diferentes sectores y de variadas maneras: 1) remoción de sedimento (erosiva), 2) acumulación de sedimento (deposicional), o bien 3) no ha habido cambios significativos (residual). El paisaje está conformado por una superficie plana de muy baja pendiente, disectada internamente en numerosas áreas levemente sobreelevadas, donde el pavimento está sujeto a condiciones tafonómicas variables. Esto se traduce en que dicho pavimento posee grados variables de preservación y madurez (inferidos a partir de los tamaños de los clastos) que están afectados por bioturbación, cobertura vegetal, erosión hídrica y deflación. Estas variantes en la estabilidad se ven claramente reflejadas en el paisaje. En las áreas menos estables, donde los tamaños de los clastos son menores en tamaño y densidad, la preservación del pavimento se encuentra comprometida, es decir, manifiesta cierta madurez $y$, por lo tanto, cierto grado de deterioro (Aldersberger et al. 2013). Asimismo, en las áreas más estables, en las que los tamaños de los clastos son más importantes y densos, es donde el pavimento cuenta con cierto grado de preservación. Los pa- vimentos mejor preservados son los que poseen la mayor concentración y densidad de artefactos líticos. En estos casos, la distribución de las pátinas en las caras de los artefactos, sumada a los eventos de talla in situ, son indicadores de que la superficie de glacis sobre las que yacen los conjuntos líticos es una geoforma estable (Adelsberger y Smith 2009). Esto es esperable en pavimentos maduros, entendidos como superficies de larga vida (Matmon et al. 2009; Aldersberger et al. 2013).

En este contexto geomorfológico, además, es factible que los conjuntos artefactuales líticos estén relativamente completos, más allá de su contexto de exposición superficial. Existen trabajos que sugieren que estos contextos de superficies con pavimentos, artefactos o fragmentos líticos del orden de $\leq 2.5 \mathrm{~cm}$ se encontrarían sujetos a procesos de migración vertical y horizontal (Aldersberger et al. 2013). Esta observación es interesante, ya que en nuestro caso, solo una fracción reducida de desechos de talla posee esas dimensiones y estos procesos permitirían explicar la baja representatividad de estos tamaños en los conjuntos que se están estudiando. Si bien esto escapa a los objetivos planteados en esta oportunidad, es claro que deben considerarse en el futuro las causas posibles de la remoción de los fragmentos más pequeños de los contextos superficiales.

Por otra parte, las superficies con pavimento menos preservado están asociadas a conjuntos artefactuales menos representativos en densidad y cuyas piezas poseen abrasión en ambas caras que, en conjunto, indica situaciones de cierta inestabilidad, es decir, cambios en las condiciones de exposición de los materiales. En estos casos, se trata de superficies asociadas a un pavimento maduro, en franco proceso de deterioro (Valentine y Harrington 2006; Matmon et al. 2009; Adelsberger et al. 2013; Ugalde et al. 2015, entre otros). 
Independientemente de la evidencia que demuestra que en el pasado hubo una mayor estabilidad o pulsos de estabilidad, factibles de ser registrados hoy a diversas escalas, consideramos que estas superficies tienen en la actualidad su estabilidad 'comprometida' aunque en grados variables. La variabilidad interna de los procesos naturales registrados en cada superficie marca, a su vez, la fragilidad ${ }^{5}$ del paisaje y, en consecuencia, de una parte del registro arqueológico.

Hacia la definición de unidad espacial de análisis: las superficies arqueológicas en RLS2

Las agrupaciones artefactuales analizadas en este trabajo están asociadas a sectores del espacio localizados dentro de superficies, que son remanentes (o relictos) de un paisaje arqueológico mayor disectado por procesos de escurrimiento y afectado por bioturbación, deflación $y$, en menor medida, depositación. Estos conjuntos líticos (como los restantes componentes del registro arqueológico) no son producto de un único evento ocupacional, sino resultado de varios eventos a lo largo del tiempo. Teniendo en cuenta que los artefactos que componen gran parte de estos conjuntos representan el 'descarte' de numerosos eventos, es fácil imaginar la acumulación de estos conjuntos como resultado de diversas y diferentes ocupaciones o usos de un lugar (time-averaging) (Stern 1994; Holdaway y Wandsnider 2006; Fanning et al. 2009).

El registro de superficie, además de los conjuntos artefactuales, está compuesto por estructuras monticulares, lineales, circulares y subcirculares aisladas y arte rupestre móvil (Somonte et al. 2010; Somonte y Baied 2011; Adris 2013) que nos hablan de una reocupación del espacio en el largo plazo (Somonte y Collantes 2010). Las superficies y el registro arqueológico que contienen, no conforman retazos homogéneos del paisaje, sino agrupaciones espaciales con características ampliamente variables en su distribución horizontal, tales como el grado de dispersión o tipo de patrón espacial del registro arqueológico. Las agrupaciones espaciales de artefactos (en sentido amplio) que hoy encontramos, comparten relaciones con los procesos naturales y antrópicos que las generaron. En

5 Con el término fragilidad nos referimos a la susceptibilidad de un paisaje al cambio cuando se desarrolla un uso o actuación sobre él, ya sea antrópico o natural (Aguiló et al. 1995). consecuencia, los atributos mencionados en este trabajo nos permiten diferenciar las agrupaciones y, más allá, reflexionar sobre el accionar de los procesos de formación. Esto sugiere que las agrupaciones de artefactos no consisten, necesariamente, de áreas de actividad o pisos de ocupación. La variabilidad en las características de los contextos presentados, dificultan tratar estas superficies como un único sitio arqueológico.

El término 'superficie arqueológica' es comúnmente utilizado en el sudeste de Australia, para aludir a contextos geomorfológicos y arqueológicos cuyos procesos tienen el potencial de variar considerablemente en el espacio, dependiendo de las características geomorfológicas puntuales del área y de su historia ocupacional. En el caso australiano, en un contexto de aridez con procesos erosivos de deflación predominantes (Fanning y Holdaway 2001), una superficie arqueológica se refiere a superficies que contienen depósitos de artefactos líticos en asociación a fogones (Rhodes et al. 2008). En nuestro caso, bajo contextos geomorfológicos diferentes donde lo que predomina es el escurrimiento superficial (sobre la deflación y depositación), los conjuntos artefactuales están asociados a soportes con arte rupestre y diversas estructuras arquitectónicas. Lo relevante del término de superficie arqueológica, es que permite vincular la variabilidad geomorfológica y arqueológica existente en un mismo espacio (glacis) a una unidad espacial de análisis concreta.

¿Desestructurando palimpsestos?: hacia una caracterización de los palimpsestos en RLS2

Las superficies arqueológicas en RLS2 presentan registros de alta (o fina) resolución asociados a lapsos temporales de ocupación cortos, además de registros de baja (o gruesa) resolución vinculados a prolongados lapsos temporales (sensu Bailey 2008). Ejemplos de la primera situación son los eventos de talla in situ identificados en diversos espacios de estas superficies arqueológicas. Estos eventos de talla puntuales, representan instantáneas (snapshots) del pasado y no son la regla, sino más bien la excepción. Del segundo caso son ejemplos las evidencias de reclamación en piezas líticas fuertemente barnizadas. A esto se suma la reclamación inferida a partir de los grados de abrasión presentes en diferentes negativos de lascado de un mismo artefacto. 
Como ya expresamos, los conjuntos de artefactos dispuestos en RLS2 representan la acumulación de eventos de 'descarte' a lo largo de la historia de uso de ese lugar, creando un palimpsesto. La noción de palimpsesto que nos interesa es aquélla que pone el énfasis en las propiedades acumulativas y transformadoras del registro arqueológico y no tanto en las de pérdida y destrucción de la evidencia. Los análisis de VML conforman un aspecto importante en este punto. Las dataciones mediante VML en Amaicha del Valle provienen de negativos de lascados de artefactos líticos de PLP, superficie localizada a menos de $1 \mathrm{~km}$ de distancia de RLS2 y que forma parte del mismo glacis que RLS1 y RLS2. Los resultados indican una edad mínima de exposición de los artefactos de 6500-5900 años AP. Muchas de estas piezas barnizadas han sido reclamadas, lo que generó nuevos negativos de lascados que también poseen barniz, pero con una intensidad menor, lo que advierte lo incipiente de su desarrollo. ${ }^{6}$ Esto es visto como la convivencia en un mismo artefacto de diversas historias de uso y, por lo tanto, de temporalidades. En estos casos, la evidencia de las primeras ocupaciones no ha sido borrada por las posteriores. Más bien, estas últimas se han sumado a las primeras, transformándolas. Esta situación es compartida por los conjuntos artefactuales líticos de RLS1, RLS2 y PLP, en los que las evidencias de reclamación ratifican esta idea (Somonte y Baied 2011; Baied y Somonte 2013).

Fuera del ámbito del área de estudio, esto puede ser equiparado con las dataciones de VML del sitio Ampajango (Catamarca), cuyos resultados de 9400-8100 años AP (Carbonelli 2014), indican la exposición de los artefactos con anterioridad ( 3 mil años) a los de PLP. En este caso, las evidencias de reclamación de los artefactos, también indican la retoma posterior $y$, por lo tanto, la acumulación en una misma pieza de diversas historias de uso. Esto mismo puede entenderse desde el arte rupestre. En RLS2, RLS2 y PLP, Adris (2013) ha identificado cinco series cronológicas o momentos de ejecución de las representaciones en dos de estos espacios (PLP y RLS2) y tres en RLS1. En ellos, si bien hay ausencia de solapamiento de motivos, éstos se presentan en forma de reciclado y de mantenimiento parcial de las representaciones. Los dos motivos que presentan

6 En estos momentos nos encontramos a la espera de los resultados de VML sobre un artefacto reclamado, con negativos de lascado con desarrollo diferencial del barniz. mantenimiento, un camélido en RLS1 y un serpentiforme en RLS2, fueron realizados en dos momentos de ejecución consecutivos, respectivamente. En cambio los reciclados muestran una a dos series alternadas, es decir, que el tiempo transcurrido entre la representación inicial y la siguiente es mayor que en las representaciones que han sido mantenidas (Adris 2013). La evidencia contextual local invita a considerar las superficies arqueológicas donde yace este registro como espacios persistentes, donde los artefactos y los soportes con arte rupestre dan cuenta de la preservación de diferentes historias de uso de ese lugar. La complejidad de estos espacios es lo que, a su vez, permite que sean considerados como palimpsestos, marcados por la acumulación y transformación y no tanto por la pérdida y destrucción de la evidencia.

Ahora bien, queda preguntarse: ¿qué tipo de palimpsesto es el que caracteriza al registro lítico artefactual de RLS2? Teniendo en cuenta las categorías de palimpsestos propuestas por Bailey (2007), las distribuciones artefactuales observadas en estas superficies arqueológicas de RLS2, están definidas por la mezcla de episodios ocupacionales espacialmente segregados (superficies con pavimento). Además, las relaciones temporales de tales conjuntos se han desdibujado y son difíciles de desenmarañar. En conjunto, estas situaciones invitan a interpretar estos espacios como palimpsestos espaciales caracterizados por una variedad de localizaciones de actividades y por diferentes grados de integridad espacial y temporal (Bailey 2007). Por su parte, el registro en estas superficies también está definido por conjuntos de materiales que, si bien forman parte de la misma superficie, en algunos casos corresponden a diferentes edades y 'lapsos de vida'. En estos casos, la asociación de artefactos de diferentes edades es realmente una agregación, debida al efecto de la mezcla de lo que originalmente fueron distintos episodios de actividad o depositación. En este sentido, RLS2 puede pensarse en términos de palimpsestos temporales (Bailey 2007). Esta explícita complejidad, en lugar de limitar, enriquece la noción de palimpsesto potenciando la lectura y las posibilidades de interpretación del registro arqueológico. Los palimpsestos en Amaicha del Valle dan cuenta de una clara convivencia horizontal, que alude a conjuntos de artefactos con historias posdepositacionales y cronológicas diferentes. 


\section{$*$ Conclusiones}

Los conjuntos líticos dispuestos sobre las superficies de glacis como RLS2 ofrecen una oportunidad interesante para el uso simultáneo y alternante de escalas de paisaje y artefacto. Estas superficies están vinculadas a un pavimento con grados variables de madurez y sobre los que actúan procesos naturales que, en conjunto, repercuten sobre las condiciones de hallazgo del registro arqueológico. Este registro, que forma parte de una misma superficie arqueológica, hoy se encuentra disectado, así como lo está el paisaje. No obstante, pudimos evaluar condiciones de mayor y menor estabilidad en esta superficie. En un extremo, los resultados indican que en la superficie de glacis donde el pavimento muestra cierto grado de preservación (indicador de estabilidad a escala del paisaje), esta superficie encuentra un correlato a escala del artefacto, a través de los indicadores de estabilidad como el barniz de las rocas y el ensamblaje. En el extremo opuesto, los datos pusieron de manifiesto que aquellos sectores donde el pavimento está sumamente deteriorado, o bien donde directamente no hay pavimento, las condiciones de inestabilidad están marcadas por procesos erosivos, cuyo accionar 'lavó' estas superficies y destruyó parte del registro. Entre estos extremos hay una variedad de grises, donde encontramos evidencia de ambas condiciones, de estabilidad e inestabilidad, reflejadas por ejemplo en la convivencia en una misma pieza de grados de abrasión con barniz de las rocas. Esto da cuenta, a escala del paisaje, del cambio en las condiciones de exposición del registro, donde la existencia de cierta estabilidad (durante la que se depositó el barniz), fue seguida de cierta inestabilidad (durante la que las piezas fueron abradidas) y viceversa.

Agradecimientos Este trabajo es resultado de las investigaciones financiadas por los proyectos de investigación PICT-2014-3448 (2015-2017) Ocupaciones humanas del Holoceno Medio y Tardío en valles intermontanos del NOA y PIUNT G-571 (2016-2017) Paisajes arqueológicos del Holoceno Medio y Tardío de valles intermontanos del NOA. A los evaluadores de este trabajo, les agradecemos el tiempo dedicado a la lectura del manuscrito y los valiosos comentarios que contribuyeron a mejorar la versión final. No obstante, los errores u omisiones vertidos en el texto son absoluta responsabilidad de los autores.

\section{$*$ Referencias citadas}

ADELSBERGER, K., J. R. SMITH, S. P. McPHERRON, H. L. DIBBLE, D. I. OLSZEWSKI, U. A. SCHURMANS y L. CHIOTTI. 2013. Desert pavement disturbance and artifact taphonomy: A case study from the Eastern Lybian Plateau, Egypt. Geoarchaeology: An International Journal 28: 112-130.

ALDERSBERGER, K. y J. SMITH. 2009. Desert pavement development and landscape stability on the Eastern Libyan Plateau, Egipt. Geomorphology 107: 178-194.

ADRIS, S. 2012. El arte rupestre entre cazadores y agricultores... paisaje ritual en cumbres calchaquíes y su vertiente occidental (Amaicha del Valle, Tucumán, Argentina). Actas del Congreso Internacional "Arqueología y Arte Rupestre" (SIARB, IFRAO), pp. 25-29. La Paz, Bolivia.

ADRIS, S. 2013. El Arte rupestre en espacios persistentes de Amaicha del Valle (Tucumán, Argentina). Mundo de Antes 8: 35-59.

AGUILÓ, M. et al. 1995. Guía para la elaboración de estudios del medio físico: Contenido y metodología. CEOTMA-MOPU, Madrid. Tercera Edición Ampliada.
ASCHERO, C. A. 1975 Ms. Ensayo para una clasificación morfológica de artefactos líticos aplicada a estudios tipológicos interpretativos. Informe inédito presentado al CONICET.

ASCHERO, C. A. 1983 Ms. Ensayo para una clasificación morfológica de artefactos líticos. Apéndices A y B. Apunte inédito para la cátedra de Ergología y Tecnología. FFyL. Universidad de Buenos Aires.

ASCHERO, C. y S. HOCSMAN. 2004. Revisando cuestiones tipológicas en torno a la clasificación de artefactos bifaciales. Temas de Arqueología. Análisis lítico. Mariano Ramos, Alejandro Acosta y Daniel Loponte (Comps.), pp. 7-25. Universidad Nacional de Luján, Luján.

BAIED, C. y C. SOMONTE. 2011. Geocronología, paleoambiente, y dinámica ocupacional durante el Holoceno Medio y Tardío en la Quebrada de Amaicha del Valle, Tucumán, Argentina. En Poblaciones Humanas y Ambientes en el Noroeste Argentino durante el Holoceno Medio, M. Mondini, J. G. Martínez, H. J. Muscio y M. B. Marconetto (Eds.), pp. 59-63. Taller de Arqueología, Córdoba. 
BAIED, C. y C. SOMONTE. 2013. Mid-Holocene Geochronology, Palaeoenvironments and Occupational Dynamics at Quebrada de Amaicha, Tucuman, Argentina. Quaternary International 299: 80-89.

BAILEY, G. 1981. Concepts, timescales and explanations in economic prehistory. En Economic Archaeology, A. Sheridan y G. Bailey (Eds.), pp. 97-117. British Archaeological Reports International Series 9 , Oxford.

BAILEY, G. 2007. Time perspectives, palimpsests and the archaeology of time. Journal of Anthropological Archaeology 26: 198-223.

BAILEY, G. 2008. Time Perspectivism: Origins and Consequences. En Time in Archaeology. Time Perspectivism Revisited, S. Holdaway y L. Wandsnider (Eds.), pp. 13-30. The University of Utah Press, Salt Lake City.

BARRIENTOS, G., L. CATELLA y F. OLIVA. 2014. The Spatial Structure of Lithic Landscapes: the Late Holocene Record of East-Central Argentina as a Case Study. Journal of Archaeological Method and Theory. DOI 10.1007/s10816-014-9220-0.

BARTON, H. 2003. The Thin Film of Human Action: Interpretations of Arid Zone Archaeology. Australian Archaeology 57: 32-41.

BINFORD, L. 1981. Bones. Ancient Men and Modern Myths. Academic Press. New York.

BORRAZZO, K. 2006. Tafonomía lítica en dunas: una propuesta para el análisis de los artefactos líticos. Intersecciones en Antropología 7: 247-262.

BORRAZZO, K. 2011. Tafonomía lítica en la estepa patagónica: experimentación y registro arqueológico de superficie. En Bosques, Montañas y Cazadores. Investigaciones arqueológicas en Patagonia Meridional. L. A. Borrero y K. Borrazzo (Comps.), pp. 127-153. Editorial Dunken, Buenos Aires.

BORRERO, L. A. 2006. Longitudinal Taphonomic Studies in Tierra del Fuego, Argentina. En Taphonomy and Zooarchaeology in Argentina, M. Gutiérrez, L. Miotti, G. Barrientos, G. Mengoni Goñalons y M. Salemme (Eds.), pp. 219-233. BAR Internacional Series 1601, Oxford.

BORRERO, L. A. 2011. La función transdisciplinaria de la Arqueozoología en el siglo XXI: restos animales y más allá. Antipodas 13: 267-274.

BORRERO, L. A. 2014. Multi-service Taphonomy. Shells, garbage and floating palimpsests. Intersecciones en Antropología. Special Issue (1): $13-20$.
CARBONELLI, J. P. 2014. Evidencias paleoambientales y de producción lítica en la cantera taller Ampajango, Valle de Yocavil (Catamarca, Argentina). La Zaranda de Ideas. Revista de Jóvenes Investigadores en Arqueología 11: 9-26.

COLLANTES, M. M. y L. M. GONZÁLEZ. 2012. Mecanismos del proceso de desertificación en el valle de Santa María, provincia de Tucumán (Argentina). Acta geológica 24 (1-2): 108-122.

COLLANTES, M. M., L. M. GONZÁLEZ y S. JEREZ. 2011. Interrelación entre desertificación, vulnerabilidad ambiental y cambio climático en el valle dez Santa María, Provincias de Tucumán y Catamarca, Argentina. XIV Congreso Latinoamericano de Geología y VIII Congreso Colombiano de Geología, Memorias, J. Gómez (Ed.), p. 162. Medellín.

COLlAnTES, M. M. y C. SOMONTE. 2007. El barniz del desierto y los procesos de reclamación en espacios persistentes: propuesta metodológica. Serie Monográfica y Didáctica, vol. 46: 29.

DIBBLE, H. L., S. J. HOLDAWAY, S. C. LIN, D. R. BRAUN, M. J. DOUGLASS, R. IOVITA, S. P. MCPHERRON, D. I. OLSZEWSKI y D. SANDGATHE. 2016. Major Fallacies Surrounding Stone Artifacts and Assemblages. Journal of Archaeological Method and Theory. DOI 10.1007/s10816-016-9297-8

DAVIES, B., S. J. HOLDAWAY y P. C. FANNING. 2015. Modelling the palimpsest: An exploratory agent-based model of surface archaeological deposit formation in a fluvial arid Australian landscape. The Holocene. DOI: 10.1177/0959683615609754.

DORN, R. 1983. Cation-ratio Dating: a new rock varnish age determination technique. Quaternary Research 20: 49-73.

DORN, R. I. 2007. Rock Varnish. En Geochemical Sediments and Landscapes, D. J. Nash y S. J. McLaren (Eds.), pp. 246-297. Blackwell, London.

DORN, R. I. 2009. The rock varnish revolution: New insights from microlaminations and the contributions of Tanzhuo Liu. Geography Compass 3:1804-1823.

DORN, R. I. y T. M. OBERLANDER. 1982. Rock Varnish. Progress in Physical Geography 6:317-367.

DURANDO, P., M. GARCÍA SALEMI y G. PLATANÍA. 1986. Estudios geomorfológicos y arqueológicos; paleoclimas, dataciones relativas y tipología a partir de paleolitos del Valle de Santa María (Provincias de Catamarca y Tucumán, República Argentina). Actas y Trabajos del VI Congreso Peruano: Hombre y Cultura Andina, Francisco Iriarte Brenner (Ed.), pp. 89-109. Universidad Inca Garcilaso de la Vega. Facultad de Ciencias Sociales, Perú. 
FANNING, P. C., S. J. HOLDAWAY, E. J. RHODES y T. G. BRYANT. 2009. The surface archaeological record in arid Australia: geomorphic controls on preservation, exposure, and visibility. Geoarchaeology: An International Journal 24: 121-146.

GARCÍA SALEMI, M. y P. DURANDO. 1985. Sobre cronologías y paleoclimas en la quebrada de Amaicha. Revista del Centro de Estudios de Regiones Secas 2 (sin paginar). Fundación CERS, TucumánCatamarca. Argentina.

GARCÍA SALEMI, M. A., G. PLATANÍA, P. DURANDO. 1988 Ms. Nuevos aportes al estudio de sitios arqueológicos superficiales a-cerámicos: barnices y cronologías relativas en el Valle de Santa María, Tucumán-Catamarca. Manuscrito en posesión de los autores.

GERMANO, F. M. 2016. Análisis funcional de instrumentos líticos barnizados en superficies arqueológicas de Río Las Salinas, Amaicha del Valle Tucumán. En Actas del XIX Congreso Nacional de Arqueología Argentina. Serie monográfica y didáctica 54: 2612.

HISCOCK, P. 1985. The Need for a Taphonomic Perspective in Stone Artefact Analysis. Queensland Archaeological Research 2: 82-95.

HOLDAWAY, S., P. FANNING y E. RHODES. 2008. Assemblage accumulation as a time-dependent process in the arid zone of western New South Wales, Australia. En Time in Archaeology. Time Perspectivism Revisited, S. Holdaway y L. Wandsnider (Eds.), pp. 110-1332. The University of Utah Press, Salt Lake City.

HOLDAWAY, S. y L. WANDSNIDER. 2006. Temporal Scales and Archaeological Lanscapes from the Eastern Desert of Australia and Intermontane North America. En Confronting Scale in Archaeology. Issues of Theory and Practice, G. Lock y B. L. Molyneaux (Eds.), pp. 183-202. Springer, New York.

HOLDAWAY, S. y L. WANDSNIDER. 2008. Time in Archaeology: An Introduction. En Time in Archaeology. Time Perspectivism Revisited, S. Holdaway y L. Wandsnider (Eds.), pp.1-12. The University of Utah Press, Salt Lake City.

LIU, T. y W. S. BROECKER. 2000. How fast does rock varnish grow? Geology 28: 183-186.

LIU, T. y W. S. BROECKER. 2007. Holocene rock varnish microstratigraphy and its chronometric application in the drylands of western USA. Geomorphology 84: 1-21.

LIU, T. y W. S. BROECKER. 2008. Rock varnish microlamination dating of late Quaternary geomorphic features in the drylands of western USA. Geomorphology 93: 501-523.
LIU, T. y W. S. BROECKER. 2008. Rock varnish evidence for latest Pleistocene millennial-scale wet events in the drylands of western United States. Geology 36(5): 403-406.

MALINSKY-BULLER, A., E. HOVERS y O. MARDERS. 2011. Making Time: 'Living floors', 'palimpsests' and site formation processes - A perspective form the open-air Lower Paleolithic site of Revadim Quarry, Israel. Journal of Anthropological Archaeo$\log y 30: 89-101$

MATMON, A., O. SIMHAI, R. AMIT, I. HAVIV, N. PORAT, E. McDONALD, L. BENEDETTI, L. y R. FINKEL. 2009. Desertpavement coated surfaces in extreme deserts present the longestlived landforms on Earth. Geological Society of America Bulletin (May/June) 121(5-6): 688-697.

MON, R. y N. MANSILLA. 1998. Estructura geológica del territorio de la Provincia de Tucumán. En Geología de Tucumán, M. Gianfrancisco, M. E. Puchulu, J. Durango de Cabrera y G. P. Aceñolaza (Eds.), pp. 147-153. Colegio de Graduados en Ciencias Geológicas de Tucumán, San Miguel de Tucumán.

OBERLANDER, T. M. 1994. Rock varnish in desert. En Geomorphology of desert environments, A.D. Abrahams, A. J. Parsons (Eds.), pp. 106-119. Chapman \& Hall, London.

PEREA, C. 1995. Mapa de vegetación del Valle de Santa María, sector oriental (Tucumán, Argentina). Lilloa 38: 120-131.

QUADE, J. 2001. Desert pavement and associated rock varnish in the Mojave Desert: How old they can be? Geology 29(9) (September): $855-858$.

RAMOS, M. 1993. Propuesta terminológica para la técnica arqueológica del ensamblaje. Arqueología 3: 199-212.

RENEAU, S. L., R. RAYMOND y C. D. HARRINGTON. 1992. Elemental relationships in rock varnish stratigraphic layers, Cima Volcanic Field, California: Implications for varnish development and the interpretation of varnish chemistry. American Journal of Science 292: 684-723.

RENEAU, S. L. y R. RAYMOND. 1991. Cation-Ratio dating of rock varnish: why does it work? En Geology 16: 937-940.

SAMPIETRO VATTUONE, M. M. y L. NEDER. 2011. Quaternary landscape evolution and human occupation in northwestern $\mathrm{Ar}$ gentina. Geological Society 352: 37-47.

SESMA, P., E. GUIDO y M. E. PUCHULU. 1998. Clima de la Provincia de Tucumán. Geología de Tucumán, M. Gianfrancisco, M. E. Puchulu, J. Durango de Cabrera y G. Aceñolaza (Eds.), pp. 41-46. Segunda edición, Colegio de Graduados en Ciencias Geológicas de Tucumán, Tucumán. 
SCHIFFER, M. 1987. Formation Processes of the Archaeological Record. University of New Mexico, Albuquerque.

SCHLANGER, S. 1992. Recognizing persistent places in Anazasi settlement systems. En Space, Time, and Archaeological Landscapes, J. Rossignol y L. Wandsnider (Eds.), pp. 91-122. Springer, New York.

SCHNEIDER, J. y P. BIERMAN. 1997. Surface dating using rock varnish. Chronometric dating in Archaeology. Advances in Archaeological and Museum Science, vol. 2, R. E. Taylor y M. Aitken (Eds.), pp. 257-384. Plenum Press, New York and London.

SAYAGO, J. M., M. M. COLLANTES y A. NIZ. 2012. El umbral de resiliencia del paisaje en el proceso de desertificación de los valles preandinos de Catamarca (Argentina). Acta geológica 24(12): 62-79.

SOMONTE, C. 2007. Espacios Persistentes y Producción Lítica en Amaicha del Valle, Tucumán. En Paisajes y Procesos Sociales en Tafi. Una mirada interdisciplinaria desde el Valle (Tucumán, Argentina), P. Arenas, B. Manasse y E. Noli (Comps.), pp. 47-78. Imprenta de la Universidad Nacional de Tucumán, Tucumán.

SOMONTE, C. y C. A. BAIED. 2011 Recursos líticos, aprovisionamiento y aspectos temporales de fuentes de abastecimiento en Amaicha del Valle, Tucumán, Argentina. Comechingonia 14: 81-97.

SOMONTE, C. y C. A. BAIED. 2013. Edad mínima de exposición de superficies en canteras-taller: Reflexiones en torno a las primeras dataciones mediante microlaminaciones del barniz de las rocas (VML) para el Noroeste Argentino. Chungara. Revista de Antropología Chilena 45(3): 427-445.

SOMONTE, C., S. ADRIS y C. A. BAIED. 2010. Arte Rupestre en sitios arqueológicos de Amaicha del Valle (Tucumán). En CD de resúmenes del VII Simposio Internacional de Arte rupestre. San Miguel de Tucumán.
SOMONTE, C. y M. M. COLLANTES. 2010. Barniz de las rocas y espacios persistentes: su abordaje desde los procesos de reclamación artefactual lítica en Amaicha del Valle (Tucumán). Mundo de Antes 5: 119-136.

STRECKER, M. R., P. CERVENY, A. L. BLOOM y D. MALIZZIA. 1989. Late Cenozoic tectonism and landscape development in the foreland of the Andes: Northern Sierras Pampeanas, $26^{\circ}-$ $28^{\circ} \mathrm{S}$, Argentina. Tectonics 8, 517-534.

TINEO, A. 2005. Estudios hidrogeológicos del valle del río Santa María, Provincia de Catamarca. Serie Correlación Geológica 20, 220 pp. Instituto Superior de Correlación Geológica, CONICET, San Miguel de Tucumán.

UGALDE, P., C. SANTORO, E. GAYO, C. LATORRE, S. MALDONADO, R. DE POL HOZ y D. JACKSON. 2015. How do surficial lithic assemblages weather in arid environments? A case study from Atacama Desert, Northern Chile. Geoarchaeology: An International Journal 30: 352-368.

VALENTINE, G. A. y C. D. HARRINGTON. 2006. Clast size controls and longevity of Pleistocene desert pavements at Lathrop Wells and Red Cone volcanoes, southern Nevada. Geology 34(7) (July): 533-536.

WANDSNIDER, L. 1998. Regional scale processes and archaeological landscape units. En Unit Issues in Archaeology: Measuring Time, Space, and Material, A. F. Ramenofsky y A. Steffen (Eds.), pp. 87102. University of Utah Press, Salt Lake City.

WISCHMEIER, W. H. y D. D. SMITH. 1978. Predicting Rainfall Erosion Losses a Guide to Conservation Planning. U.S. Department of Agriculture, Agriculture Handbook 537, p 43, United States. 
